بناء اختبار معرفي لمقرر الهوكى لطلاب المرحلة التخصصية بكلية التربية الرياضية- جامعة أسيوط لطية المرجة

أ.د/ محمود عبد الحليم عبد الكريم

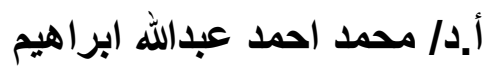

م.م/ خالا ابو السعود عبدالله

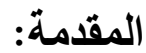

إن أبرز ما يميز عالمنا المعاصر ذللك التطور في جميع جوانب الحياة

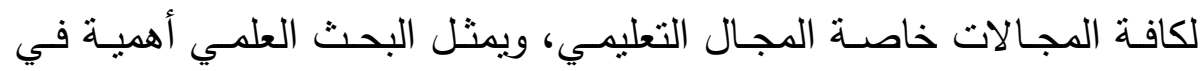
تحقيق التقدم الحضاري في المجالات المختلفة سواء كان بناءا أو تطوبرا أو تقويما.

ويعتبر تقويم المجال المعرفي لبرامج التربية الرياضية مكونا هاما من

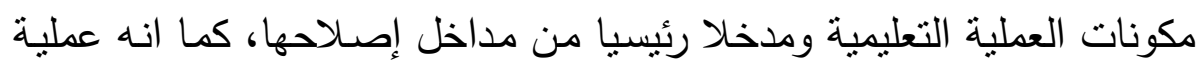

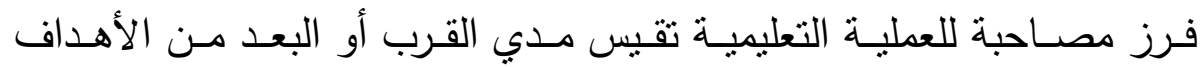
المرسومة بأسلوب علمي موضوعي يتصف بالاستمرار والشمول والدقة.

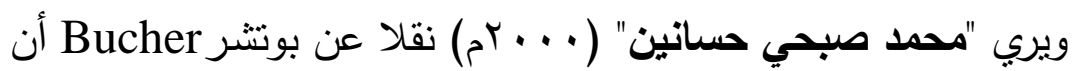
أهمية استخدام أساليب التقويم المناسبة في التربية الرياضية لمعرفة مواطن القوة

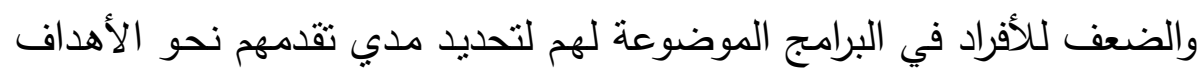
المرسومة، ولقد ثبت بالبحث العلمي ان جميع الاختبارات تعتبر من أكثر أدوات التقويم استخداما أن لم يكن أكثرها علي الإطلاق. (س إ:؟ به).

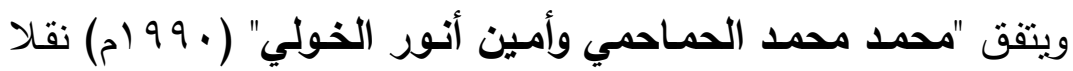
عن كارول وآخرون Carrol and others مع كل من ليلي السيد فرحات

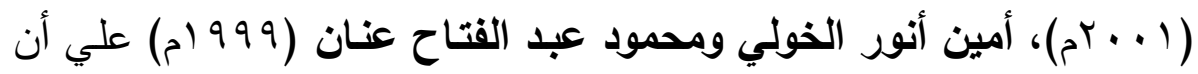
المجال المعرفي له صلة وثثقة بالمجال الحركي ولعل ما يؤيد ذلك تسمية أول

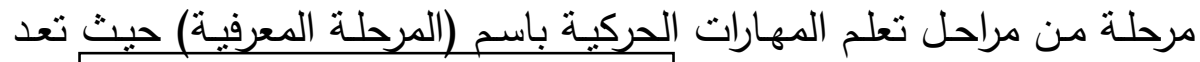
مجلة أسيوط لعلوم وفنون التربية الرياضية 
المرحلة المعرفية من أولي مراحل التعلم الحركي للمهارات وأكثرها أهمية والتي

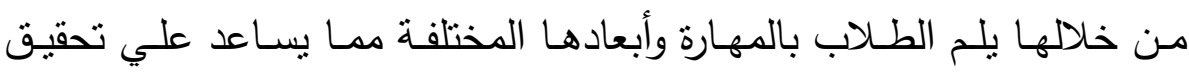

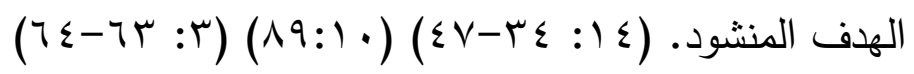

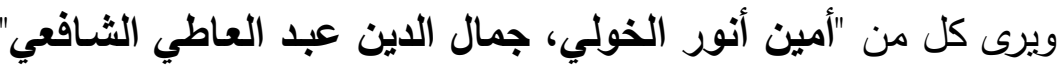

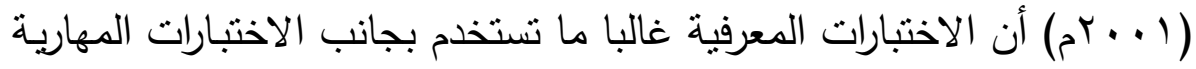

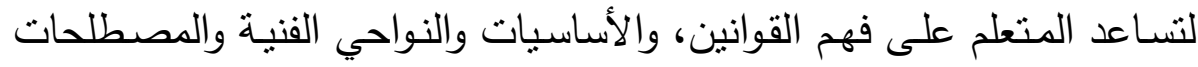

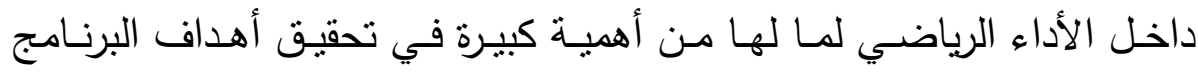

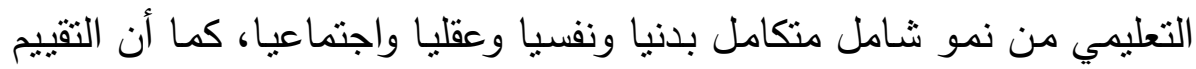

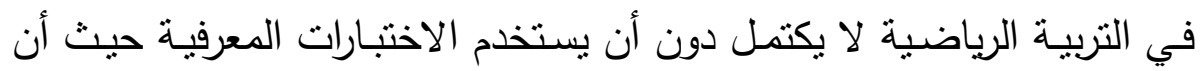
النقويم والقياس يفيدونا كوسيلة لتحديد مدي النجاح الذي وصلنا إلية كعاملين في هذا المجال وذللك في سبيل تحقيق أهداف العملية التعليمية (؟:9 ب). ويثير "محمد محمد الحماحمي" (Y99 ام) نقلا عن الرابطة الأمريكية

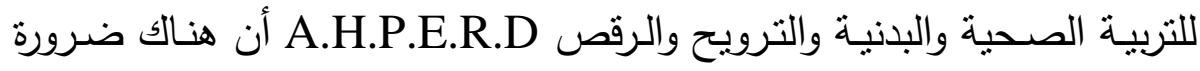

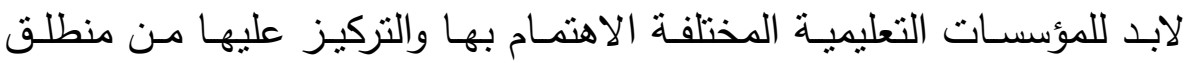

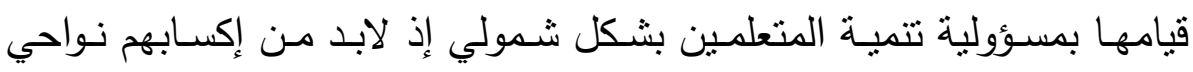

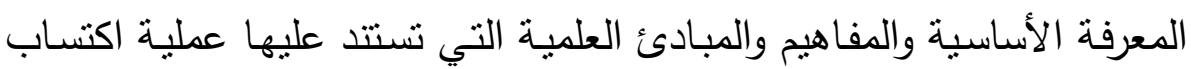

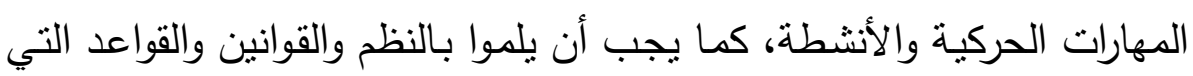

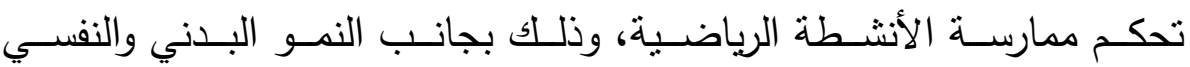

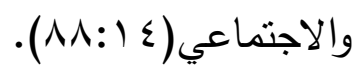

كما أنه كلما ازداد إدراك وفهم المتعلم للنواحي المعرفية الخاصة بمهارة

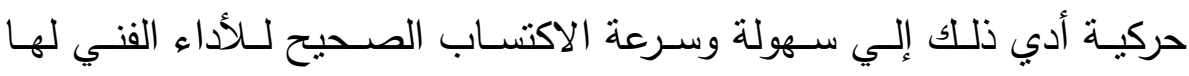
.$(\wedge \wedge: r)$ 
ويؤكد" ايزابيل ولكر Isabel Walker " ( ( . بآم) إلى أن علماء

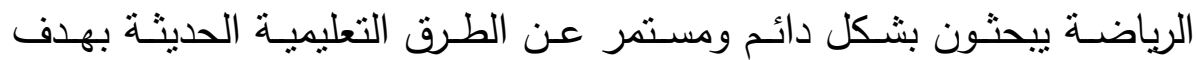

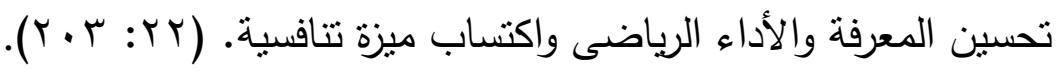

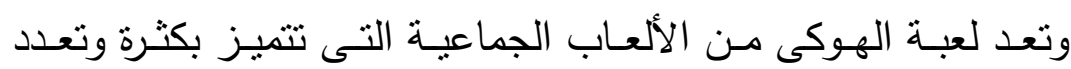

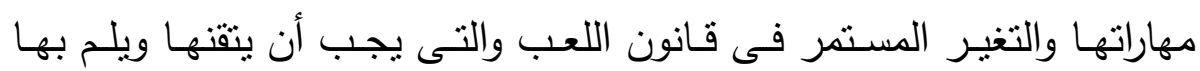

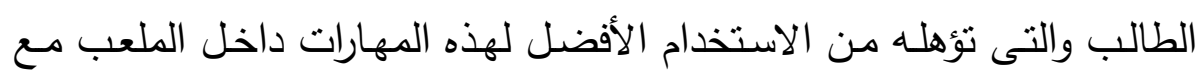

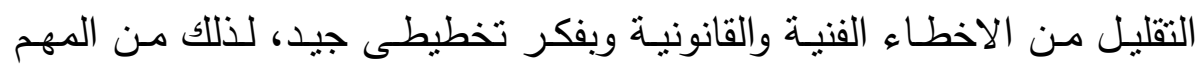

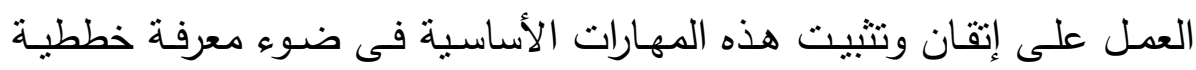
وقانونية وبطرق مختلفة تتتاسب مع طبيعة هذه اللعبة.

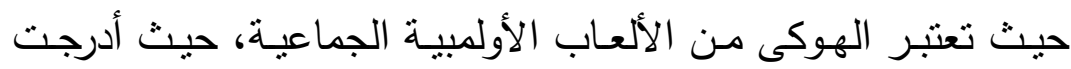

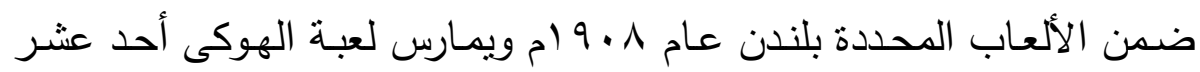

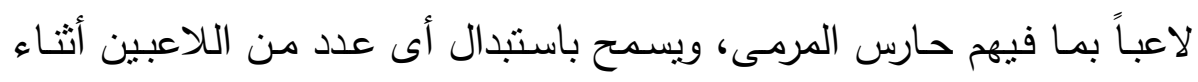

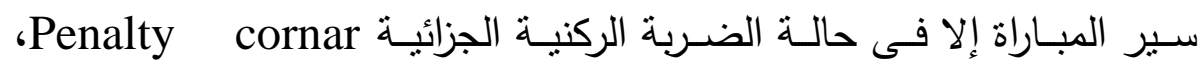

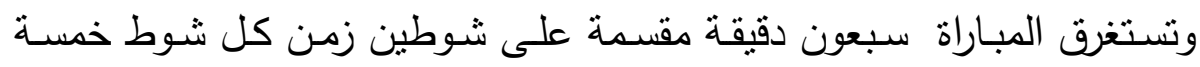

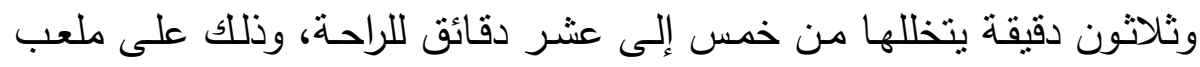

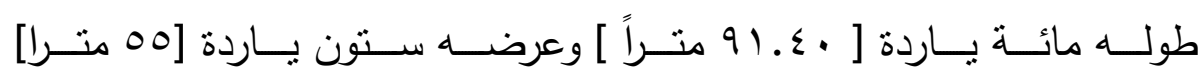
.(0:11)

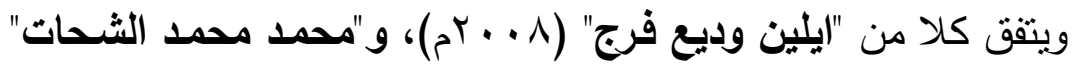

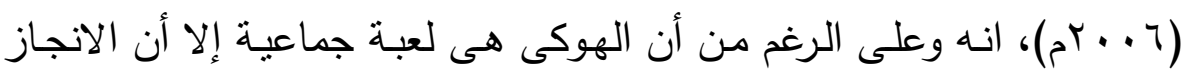

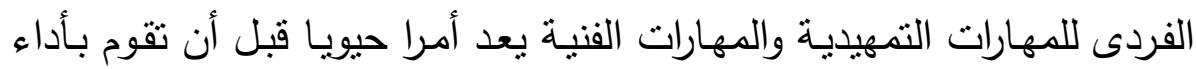

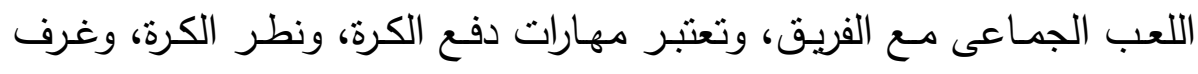

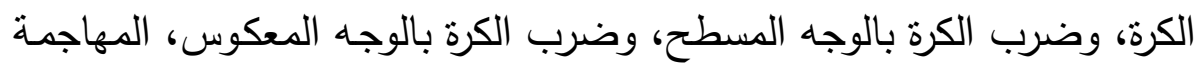
والتصويب والتحرك بالكرة (دفع - دحرجة- محاورة) أو بدونها، والدفاع جميعها

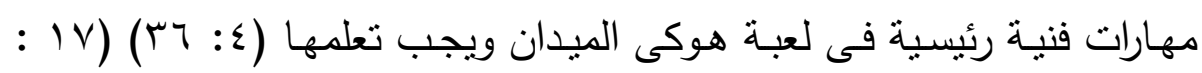


كمـا يـرى "محمـد محمـــ الثـحات" (99V (م) انـه يتطلب الوصـول باللاعب إلى المستوي الرياضي العالي إلى إتقان المهارات الحركية الأساسية

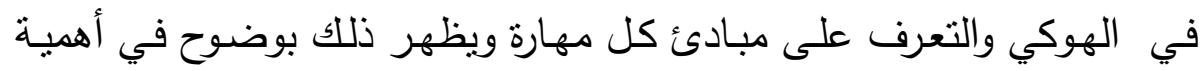

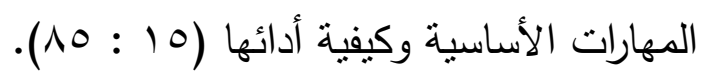

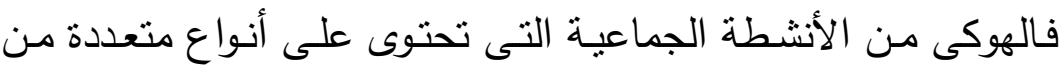

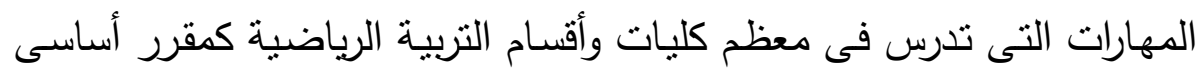
يستدعى خضوعها الى الأسـاليب التعليميـة والتربويـة التى اقرهـا علمـاء التربيـة وذلك للتعرف على أفضل أساليب التعليم والتعلم. ولقد شهدت الآونة الأخيرة تطورا ملحوظا في لعبة الهوكى مما جعلها احدي الالعـاب التي تفرض نفسـها كإحدي أنشطة الرياضـات الترويحيـة من جانب وأنشطة رياضـة المستوب الرفيع من جانب أخر وذلك بفضل التطورات المستمرة في قانون ومهارات وأدوات وطرق وخطط اللعب والتي بدونها لا يظهر الطابع المميز لهذه الرياضة. ومن خلال ما توصل إلية الباحثون من الدراسات المرجعية في مجال الهوكى لاحظوا ندرة في وجود اختبارات معرفيـة تقيس الجوانب المعرفية في لعبة الهوكى لطلاب المرحلة التخصصية بكليات التربية الرياضية رغم أهميتها الحيوية في معرفة مقدار الحصائل المعرفية في هذه اللعبة.

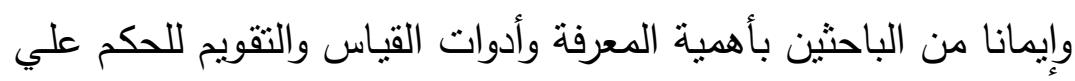
مدي تقدم العملية التعليمية نحو أهدافها سعي الباحثين لبناء اختبار معرفي

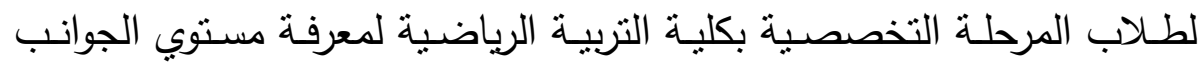
المعرفية لديهم في لعبة الهوكى. هدف البحث:

يهدف البحث إلي بناء اختبار معرفي في لعبة الهوكى لطلاب المرحلة التخصصية بكلية التربية الرياضية- جامعة أسيوط. مجلة أسيوط لطوم وفنون التربية الرياضية 
هل الاختبـار المعرفي قيد البحث يقيس الجوانب المعرفيـة في لعبـة الهوكى لطلاب المرحلة التخصصية بكلية التربية الرياضية-جامعة أسيوط ؟

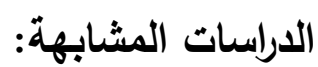

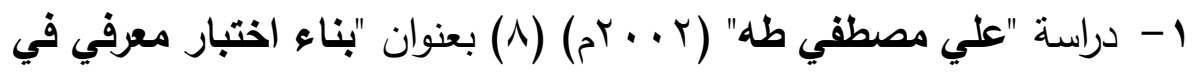

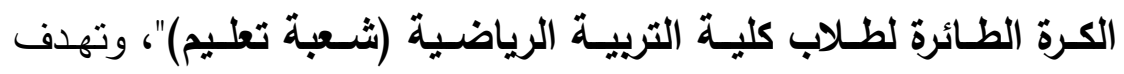
الدراسـة إلـي بنـاء اختبـار معرفي في الكرة الطـائرة لطـلاب كليـة التربيـة الرياضية (شُعبة تعليم)، ووضـع معايير تائية T score مقابلة لدرجات

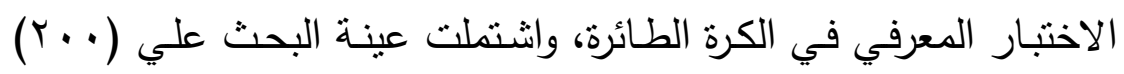
طالب، وقد استخدم الباحث المنهج الوصفي ، وكانت أهم نتائج البحث بناء اختبار معرفي في الكرة الطائرة لطلاب كلية التربية الرياضية(شعبة التبات تعليم).

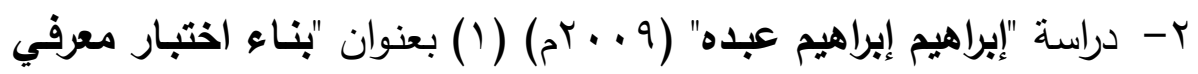
في رياضة الملاكمة لطلاب كليات التربية الرياضية"، وتهدف الدراسة إلي إيلي بنـاء اختبـار معرفي في رياضــة الملاكمـة لطـلاب كليـة التربيـة الرياضية (ثـعبة تدريس)، وتحديد مسـتويات معياريـة لتحديـ مستوي المعرفـة في رياضــة الملاكمـة، واشتملت العينة علي ( . . ب) طالب، استخدم الباحث المنهج الوصفي، وكانت أهم نتائج البحث قدرة الاختبار المعرفي المصمم علي التفريق بين الطلاب الممتازين والضعاف فالجوانب المعرفية المرتبطة وحة برياضة الملاكمة ووضع مستويات معيارية للاختبار للتعرف علي مستوي

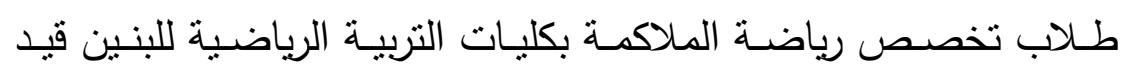

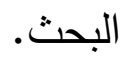

r- دراسة "إيمان سيد احمد" ( • ( • rم) (0) بعنوان "برنامج الكترونـي مقترح

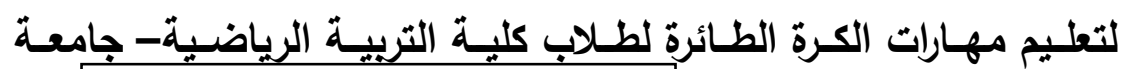
مجلة أسيوط لعلوم وفنون التربية الرياضية 
أسـيوط"، وتهدف الدراسـة إلـي تصـميم برنـامج الكترونسي على الثـبكة

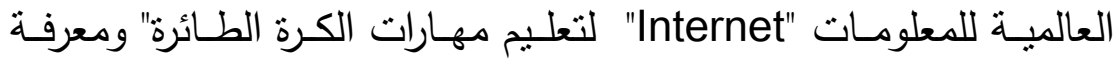
تأثنره على: التحصيل المعرفي في الكرة الطـائرة لطـلاب الفرقة الأولى بكلية التربية الرياضية جامعة أسبوط- الأداء المهاري في الكرة الطائرة

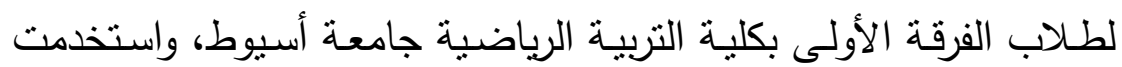

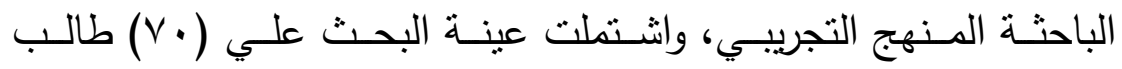
وطالبة، وكانت أهم نتائج البحث البرنامج التعليم الالكتروني المقترح على ولى الانترنت سـاهم بطريقة ايجابيـة في تعليم المهارات الأساسية في الكرة الطـائرة "قيـد البحـث"، والتحصـيل المعرفي لأفراد المجموعـة التجريبيـةالبرنامج التعليم الالكتروني المقترح على الانترنت سـاهم بطريقة ايجابيـة

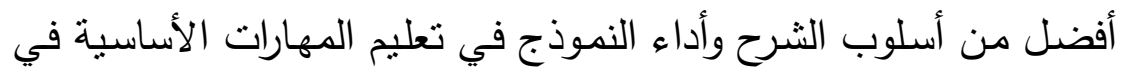
الكرة الطائرة "قيد البحث"، وكذللك التحصيل المعرفي.

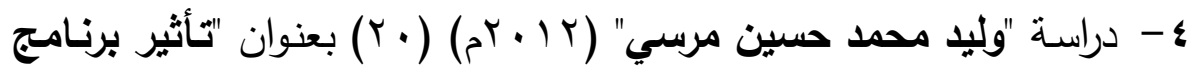

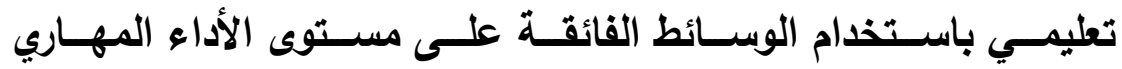
والتحصيل المعرفي في كرة السلة لاي طلاب الفرقة الثانية بكلية التربية الرياضـية- جامعـة أسـيوط"، واسـتهدفت الدراسـة تصـيم برنـامج تعليمي مبنى على اسـتخدام الوسـائط الفائقة ومعرفـة تـأثيره على مسـتوى الأداء المهارى والتحصيل المعرفي في كرة السـلة لطـلاب الفرقـة الثانيـة بكليـة

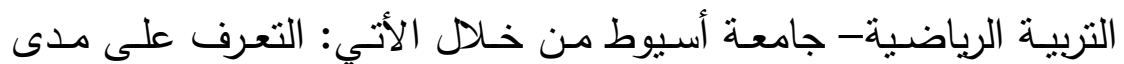
فعاليـة البرنامج التعليمي على مستوى الأداء المهارى للمهارات الأساسية في كـرة السـلة قيـد البحـث، التعـرف على مسـتوى التحصـيل المعرفي للمحتوى العلمي للمهارات الأساسية في كرة السلة قيد البحث من حيث تاريخ اللعبة، الأداء الفنى لكل مهارة من المهارات الأساسية، مواد القانون

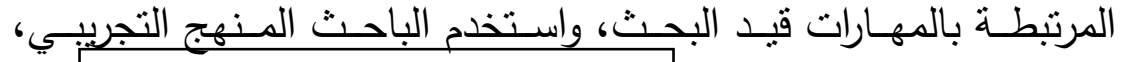
مجلة أسيوط لعلوم وفنون التربية الرياضية الئية 
واثتنملت عينة البحث علي (• ؛) طالب، وكانت أهم النتائج أن البرنامج

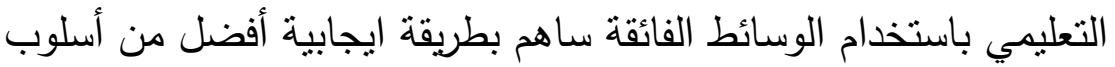

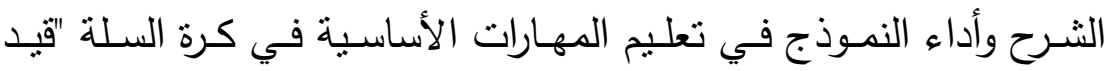

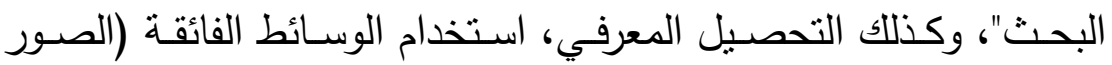

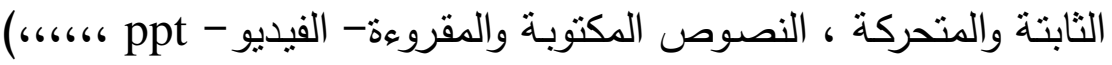

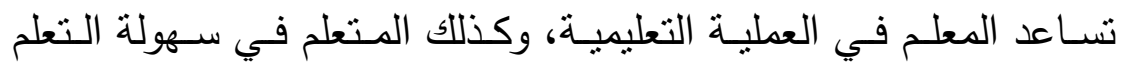
واكتساب المعلومات والمعارف النظرية والعملية.

$$
\text { منهج البحث: البحث: }
$$

استخدم الباحثون المنهج الوصفي نظرا لملاءمته لطبيعة الدراسة.

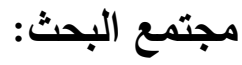

تمثل مجتمع البحث في طلاب الفرقة الثالثة بكلية التربية الرياضية

$$
\begin{aligned}
& \text { جامعة أسيوط للعام الجامعي (10 • r-7 1 • r م). }
\end{aligned}
$$

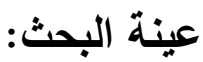

اختار الباحثون عينة البحث بالطريقة العمدية من طلاب الفرقة الثالثة

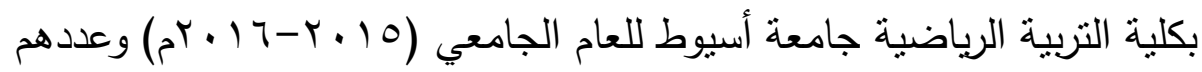

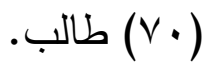

خطوات بناء الاختبار المعرفي:

قام الباحثون بـالإطلاع على عدد من المراجـع العلميـة التي تتاولت

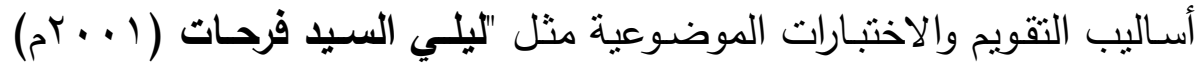

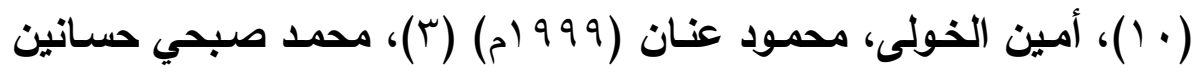

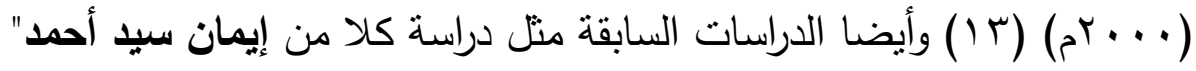

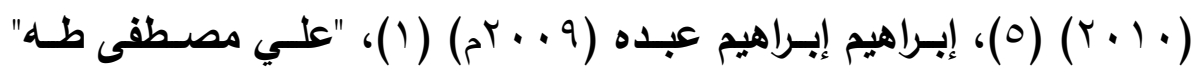




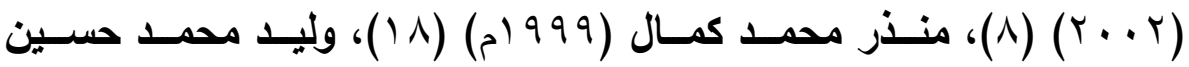

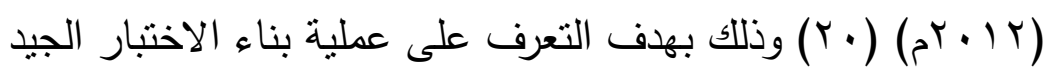

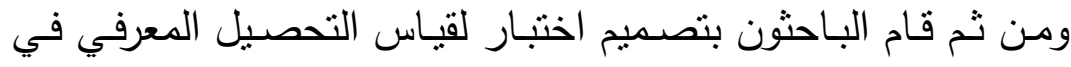
المعلومات المعرفية المرتبطة بلعبة الهوكى وقد اتبع الباحثون الخطوات الآتية: تحديد الهذف من الاختبار:

في ضوء أهداف البحث تم تحديد الهدف من الاختبار المعرفي وتمثل في قياس مستوى التحصيل المعرفي لعينة البحث "طلاب الفرقة الثالثة بكلية التربية الرياضية جامعة أسيوط" في المعلومات المعرفية من المعارف والحقائق

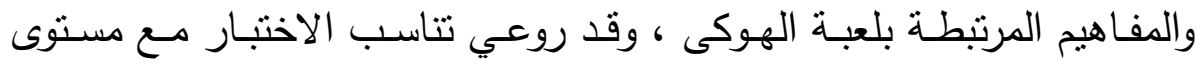
المرحلة السنية لعينة البحث.

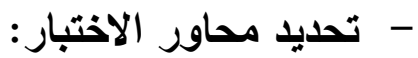

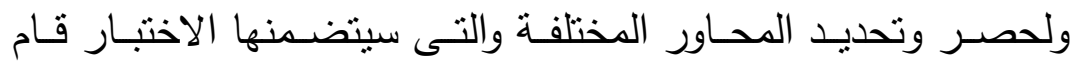

الباحثثن بـالرجوع إلى توصيف مقرر تدريس الهوكى للفرقة الثالثة باللائحسة الداخليـة لكليـة التربيـة الرياضية بجامعـة أسيوط والدراسـات والمراجـع العلميـة

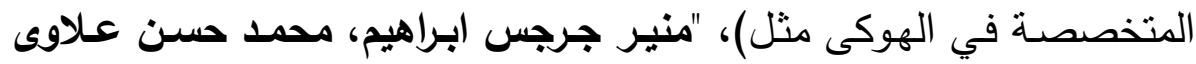

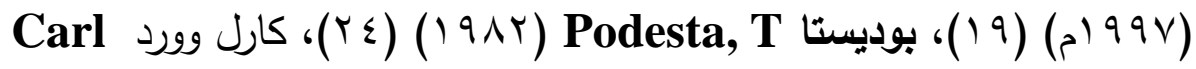

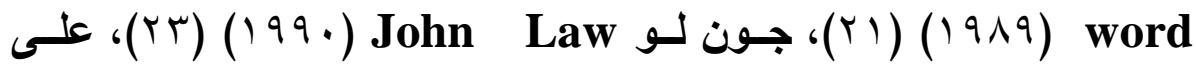

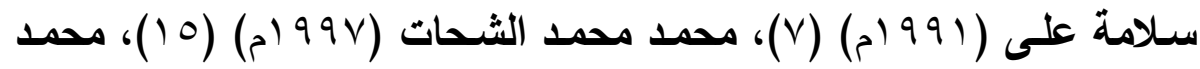

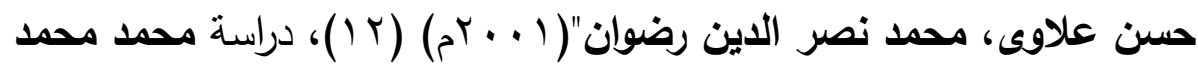

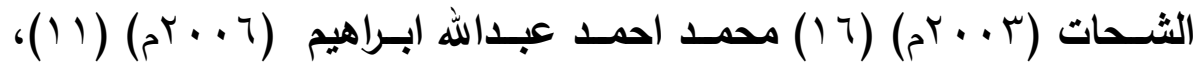

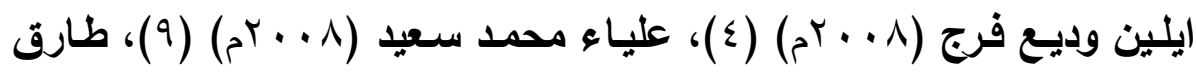

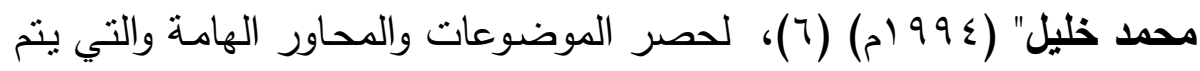
عليها التركيز أثناء بناء الاختبار المعرفى. 
وقام الباحثون باعداد استمارة لاستطلاع رأي السـادة الخبراء في طرق التدريس والهوكى وعددهم ( • () خبراء مرفق (1) للتعرف على محاور الاختبار المعرفى وذلك في ضوء الهدف العام، والأهداف التعليمية/ السلوكية، ومحتوى التوصيف الخاص بالمقرر والمعلومات المعرفية المرتبطة، والمراد قياس مستوى تحصيل الطلاب فيها مرفق(ب)، واستخدم الباحثون النسبة المئوبـة لأراء السادة الخبراء بهدف استخلاص المحاور الرئيسية للاختبار الأكثر مناسبة وارتضسي الباحثون بنسبة ، ^^\% وجدول ( ) يوضح ذلك : جدول (1) جوضح (1)

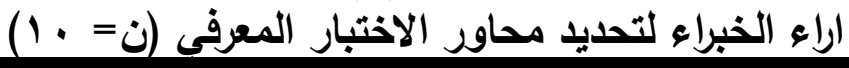

\begin{tabular}{|c|c|c|c|}
\hline النسبة المئوية & 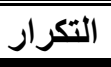 & محسـاور الاختبـــار & م \\
\hline$\%$ & 1. & نشأة وتاريخ هوكي الميدان & 1 \\
\hline$\% 1 \ldots$ & 1. & مهارات هوكي الميدان & r \\
\hline$\%$ r. & r & الأدوات والأجهزة المستخدمة في هوكي الميدان & $r$ \\
\hline$\% 9$. & 9 & النواحي القانونية & $\varepsilon$ \\
\hline$\% \wedge$. & $\wedge$ & خطط لعب & 0 \\
\hline
\end{tabular}

يتضح من جدول(1) ان محور الادوات والاجهزة المستخدمة قد حصل

علي نسبة أقل من •^^\% وبالتالي تم استبعادهم واصبح عدد محاور الاختبار ( ؟) وجدول (r) يوضح ذللك.

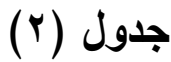

$$
\text { محاور الاختبار المعرفي (ن = - . (1) }
$$

\begin{tabular}{|c|c|c|c|}
\hline النسبة المئوية & التكرار & محــاور الاختبـــار & م \\
\hline$\% 1 \ldots$ & 1. & نشأة وتاريخ هوكى الميدان & 1 \\
\hline$\%$ & 1. & مهارات هوكى الميدان & $r$ \\
\hline$\% 9$. & 9 & النواحى القانونية & $r$ \\
\hline$\% \wedge$. & $\wedge$ & خطط وطرق اللعب & $\varepsilon$ \\
\hline
\end{tabular}

- تحديد الأهمية النسبية لمحاور الاختبار : مجلة أسيوط لعلوم وفنون التربية الرياضية 
قام الباحثون استتادا على توصيف مقرر تدريس الهوكى لطلاب الفرقة الثالثة باللائحة الداخلية لكلية التربية الرياضية بجامعة أسيوط باعداد استمارة

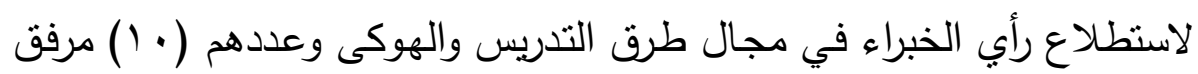
(1) وذلك لتحديد الأهمية النسبية لكل محور من محاور الاختبار مرفق (ب)،

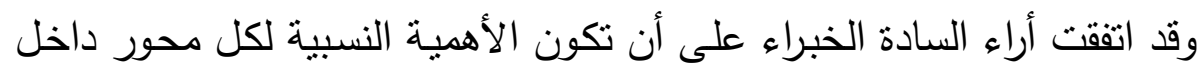

$$
\text { الاختبار كما في جدول (ب). }
$$

جدول (r)

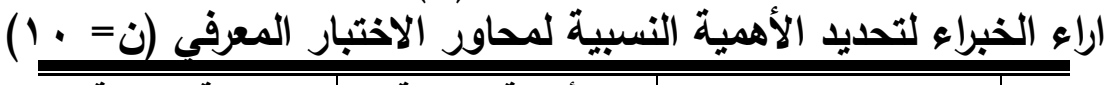

\begin{tabular}{|c|c|c|c|}
\hline النسبة المئوية & الأهمية النسبية & محاور الاختبار & p \\
\hline$\% 1 \ldots$ & $\% 1$. & نشأة وتاريخ الهوكى & 1 \\
\hline$\% 1 \ldots$ & $\% \leq r$ & مهارات الهوكى & $r$ \\
\hline$\% \wedge$. & $\%$ ro & النواحي القانونية & $r$ \\
\hline$\% 9$. & \%rr & خطط وطرق اللعب & $\varepsilon$ \\
\hline
\end{tabular}

ويتضح من جدول(r) ان محور نشأة وتاريخ الهوكى حصل علي نسبة

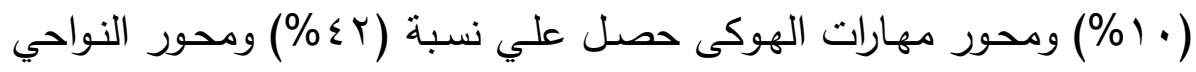
القانونية حصل علي نسبة (\%)\% ومحور خطط وطرق اللعب حصل علي نسبة (r)\%).

- صياغة مفردات الاختبار :

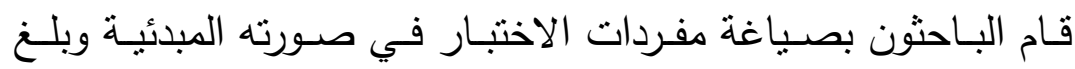

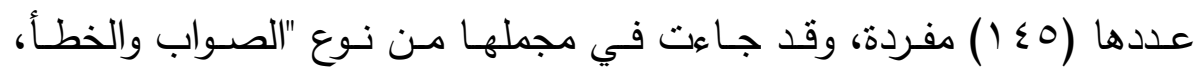
الاختيار من متعدد، وإكمال النقاط" وقد روعي في هذه المفردات ما يلي: أن تقيس مستوى التحصيل المعرفي في الاربعة محاور الرئيسية للاختبار

$$
\text { المعرفى. }
$$

أن تقيس كل مفردة ناتج تعلم معين. أن تكون مناسبة لسن ومستوى العينة. 
أن تكـون خاليـة مـن التلميحـات التـي تقـود إلـى الإجابـة الصـحيحة والخاطئة.

أن تتسم بالثمول والدقة العلمية والوضوح، وعدم احتمال اللفظ لأكثر من مدلول، وتتسم بالبساطة والسهولة اللغوية. - تحديد المستويات المعرفية للاختبار :

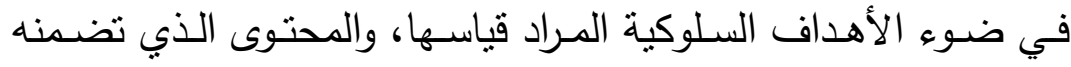

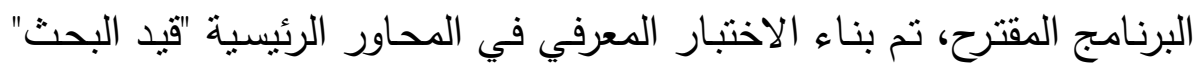

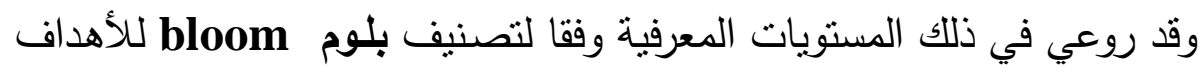

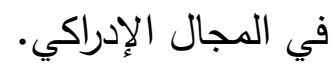
إعداد الصورة الأولية للاختبار وعرضها على المحكمين :

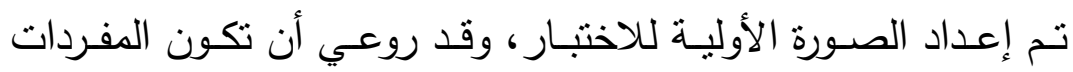

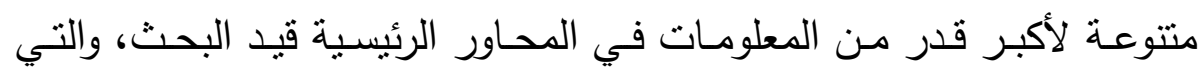

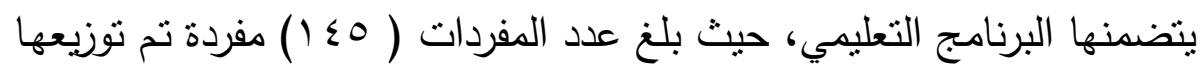

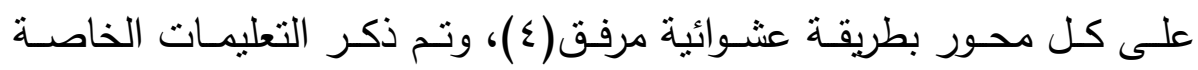

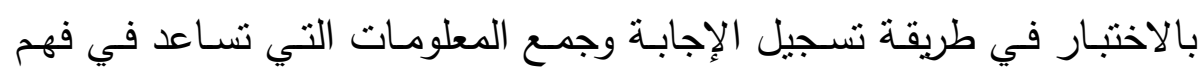

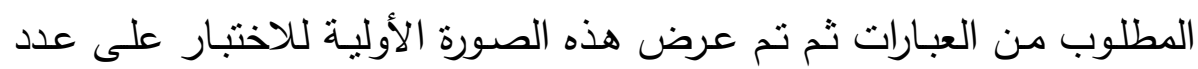

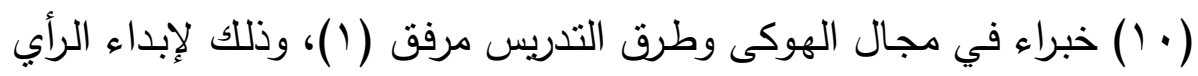

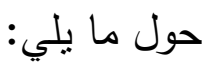
- مناسبة الأهداف التعليمية الموضوعة لـفردات الاختبار . - الدقة العلمية والصياغة اللغوية لدفردات الاختبار .

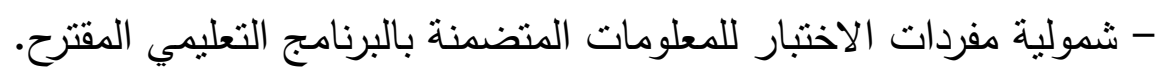
- مناسبة الاختبار لطبيعة ومستوى العينة.

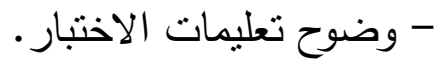
- إبداء أية ملاحظات أو مقترحات. - مدى صلاحية الاختبار للتطبيق. 
واستخدم الباحثون النسبة المئوية لأراء السادة الخبراء بهذف استخلاص

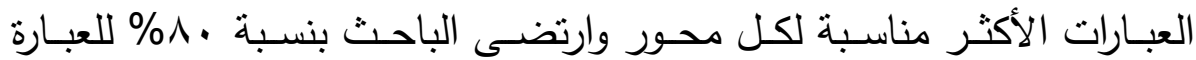
وجدول (乏) يوضح ذللك.

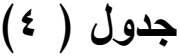

النسب المئوية لعبارات الاختبار المعرفي حب اراء الساده الخبراء (ن) (1.

\begin{tabular}{|c|c|c|c|c|c|c|c|c|c|c|c|c|c|}
\hline \multicolumn{2}{|c|}{ خطط وطرق } & \multicolumn{4}{|c|}{ قاتون الهوكى } & \multicolumn{6}{|c|}{ مهارات الهوكى } & \multicolumn{2}{|c|}{ تاريخ ونشاة } \\
\hline $\begin{array}{l}\overline{7} \\
\overline{3} \\
\frac{3}{3}\end{array}$ & $\underset{30}{9}$ & $\frac{\sqrt[7]{3}}{3}$ & $\underset{30}{3.5}$ & $\frac{\overline{7}}{3}$ & $\underset{3}{3}$ & $\frac{\overline{7}}{3}$ & $\underset{30}{3.3 .}$ & $\frac{\overline{7}}{3}$ & $\underset{30}{3.9}$ & $\frac{\overline{7}}{3}$ & $\underset{3}{3}$ & $\frac{7}{3}$ & $\underset{30}{3}$ \\
\hline$\% 9$. & 7 & $\% 9$. & $9 \wedge$ & $\% 1 \ldots$ & 1 & $\% 1 \ldots$ & 114 & $\% \wedge$ & $0 \leq$ & $\% 1 \ldots$ & r & $\% \wedge$. & 0 \\
\hline$\% 1 \ldots$ & 19 & $\% \wedge$. & $1 \ldots$ & $\% 9$. & $\varepsilon$ & $\% 1 \ldots$ & $11 \varepsilon$ & $\% 1 \ldots$ & ov & $\% 9$. & $r$ & $\% \wedge$. & $\wedge$ \\
\hline$\% q$. & $r$. & $\% 1 \ldots$ & 1.1 & $\% 1 \ldots$ & 9 & $\% 9$. & 117 & $\% 1 \ldots$ & 09 & $\% \wedge$. & V & $\% q$. & Ir \\
\hline$\% \wedge$. & rT & $\% q$. & 1.7 & $\% \circ$ & 1. & $\% \wedge$. & 111 & $\% 9$. & Tr & $\% 9$. & 11 & $\% 1 \ldots$ & 17 \\
\hline$\% \varepsilon$. & rV & $\% \wedge$. & $1 \cdot 1$ & $\% 9$. & $1 \pi$ & $\% 9$. & IT. & $\% \wedge$. & 77 & $\% 1 \ldots$ & $1 \varepsilon$ & $\% \wedge$. & $r \varepsilon$ \\
\hline$\% 9$. & ו & $\% 9$. & 11. & $\% \wedge$. & 10 & $\% 7$. & ITY & $\% 9$. & 71 & $\% \wedge$. & IV & $\% 7$. & rq \\
\hline$\% 9$. & דr & $\% \varepsilon$. & 111 & $\% 9$. & 11 & $\% \varepsilon$. & $1 T \varepsilon$ & $\% \wedge$. & $V$. & $\% 9$. & YI & $\% 1 \ldots$ & r \\
\hline$\% 1 \ldots$ & rᄉ & $\% 9$. & $11 \mathrm{~V}$ & $\% 1 \ldots$ & $r r$ & $\% \circ$. & $1 \% 7$ & $\% 9$. & VY & $\% 1 \ldots$ & ro & $\% 9$. & זד \\
\hline$\% \wedge$. & $\varepsilon$. & $\% \wedge$. & 119 & $\%$ r. & $\varepsilon r$ & $\% \circ$. & ITA & $\% 0$. & $V \varepsilon$ & $\% 9$. & TT & $\% \circ$. & vo \\
\hline$\% 9$. & 07 & & & $\% 9$. & $\leq 7$ & $\% 9$. & T. & $\%$ \%. & $\vee q$ & $\% \vee$. & rᄉ & $\% 9$. & $V V$ \\
\hline$\% 9$. & 7. & & & $\% 1 \ldots$ & $\leq 9$ & $\%$ \%. & |T| & $\% \wedge$. & $\wedge 1$ & $\% 9$. & r. & $\% \wedge$. & 19 \\
\hline$\% 1 \ldots$ & 70 & & & \%ч. & or & $\% \leq$. & אחו & $\%$ \%. & ז & $\% 9$. & rr & $\% \wedge$ & 119 \\
\hline$\% 1 \ldots$ & NT & & & $\% 1 \ldots$ & 00 & $\%$ \%. & $1 \pi \varepsilon$ & $\% 7$. & $\Lambda \varepsilon$ & $\% 7$. & $r \varepsilon$ & $\% 9$. & rT \\
\hline$\% 9$. & 10 & & & $\% 9$. & 01 & $\% \leq$ & ס & $\% 9$. & ᄉT & $\% 9$. & o & $\% 1 \ldots$ & ד \\
\hline$\% 9$. & $\Lambda V$ & & & $\% 9$. & 71 & $\% 1 \ldots$ & ITV & $\% \vee$. & $\wedge \wedge$ & $\% 0$ & rV & $\% \vee$ & IT \\
\hline$\% 9$. & 9 . & & & $\% 1 \ldots$ & $7 \leq$ & $\% 9$. & 1149 & $\% \wedge$. & 91 & $\% 9$. & rq & $\% 7$. & $\mid \leq 1$ \\
\hline$\% \wedge$ & 94 & & & $\%$ \%. & $7 V$ & $\%$ \%. & $1 \leq$. & $\% 7$. & 94 & $\% \wedge$. & $\Sigma 1$ & & \\
\hline$\% 1 \ldots$ & $1 . r$ & & & $\% q$. & 79 & $\% \leq$. & $1 \leq r$ & $\% 1 \ldots$ & 90 & $\% q$. & $\varepsilon r$ & & \\
\hline$\% 9$. & 1.0 & & & $\% 1 \ldots$ & $V_{1}$ & $\% \wedge$ & $1 \leqslant r$ & $\% q$. & $9 V$ & $\% 1 \ldots$ & $\varepsilon \varepsilon$ & & \\
\hline$\% \wedge$. & 110 & & & $\% 9$. & VT & $\% 1 \ldots$ & $1 \leq \varepsilon$ & $\% 1 \ldots$ & 99 & $\% 1 \ldots$ & $\leq 0$ & & \\
\hline$\% 9$. & $|M|$ & & & $\% \wedge$. & VI & $\% 9$. & $1 \leq 0$ & $\% 9$. & $1 . r$ & $\% 9$. & $\leqslant V$ & & \\
\hline$\% 9$. & IrT & & & $\% 1 \ldots$ & $\mathrm{VA}$ & & & $\% 1 \ldots$ & $1 \cdot \varepsilon$ & $\% \wedge$. & $\varepsilon \lambda$ & & \\
\hline$\% 1 \ldots$ & iro & & & $\%$ \%. & $\Lambda$. & & & $\% q$. & $1 \cdot V$ & $\% 9$. & 0. & & \\
\hline$\% 1 \ldots$ & ITV & & & $\% \wedge$. & $9 \leq$ & & & $\% \wedge$. & 1.9 & $\% \wedge$. & 01 & & \\
\hline & & & & $\% 9$. & 97 & & & $\% 9$. & 111 & $\% \vee$. & or & & \\
\hline
\end{tabular}

مجلة أسيوط لعلوم وفنون التربية الرياضية 


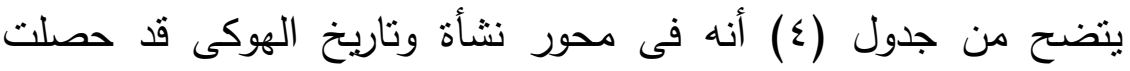

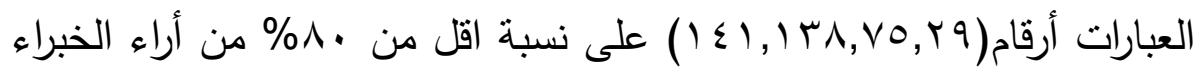

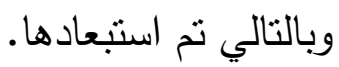

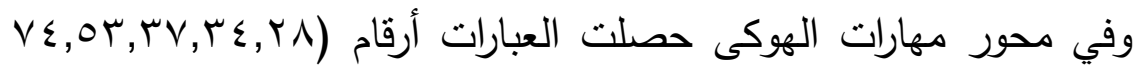

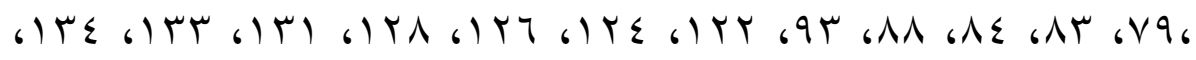

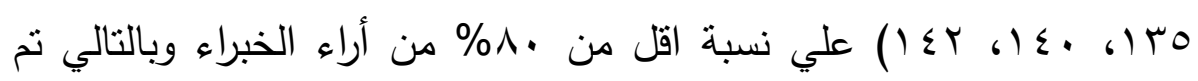

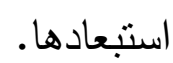

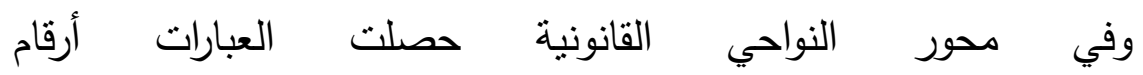

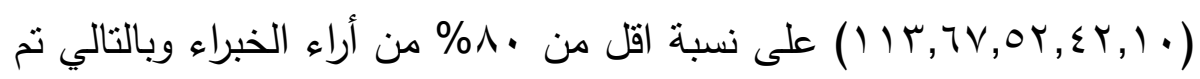

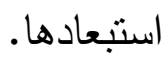

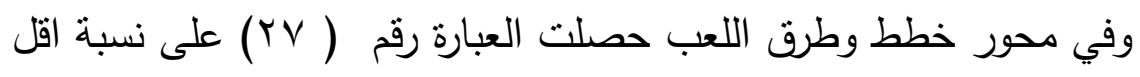
من •^\% من أراء الخبراء وبذلك تم استبعاد عدد (•r) عبارة على المحاور

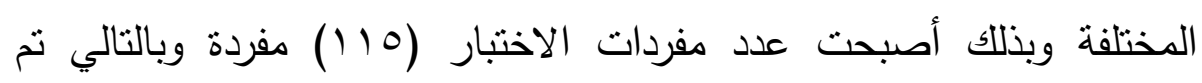
استبعادها.

معامل السهولة والصعوية والتمييز لمفردات اختبار التحصيل المعرفى:

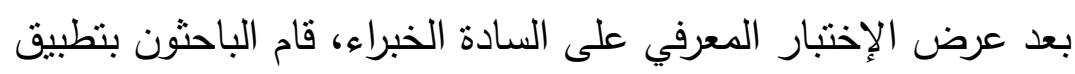

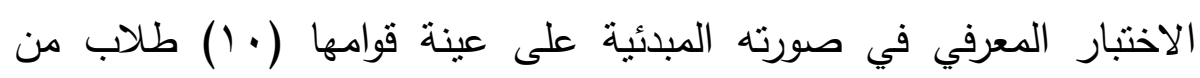

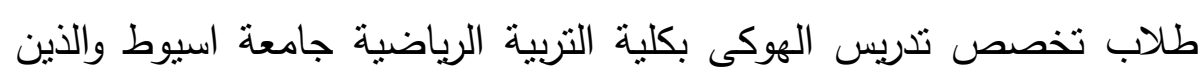

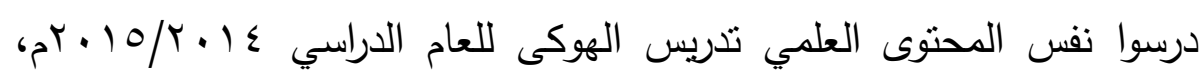

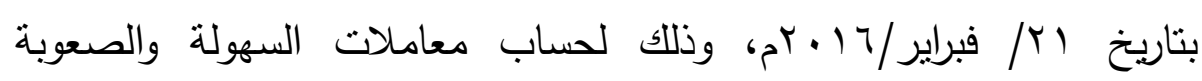
لمفردات الاختبار باستخدام المعادلة التالية : عدد الطلاب الذين أجابوا إجابة صحيحة على كل مفردة معامل السهولة = عدد الطلاب الكلي مجلة أسيوط لعلوم وفنون التربية الرياضية 
والعلاقة بين معامل السهولة ومعامل الصعوبة علاقة عكسية، بمعنى أن مجموعهم يساوي الواحد الصحيح كالتالي:

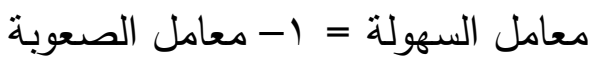

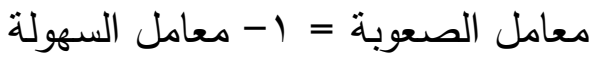

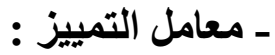

لحساب معامل التمبيز ، رتبت درجات العينة تنازليا، لتحديد الـr \% ألعليا وكذللك الـr Y \% السـفلى، بهدف تحديــ معامـل التميـز لكـل عبـارة باسـتخدام

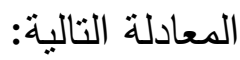
معامل التمييز= عدد الإجابات الصحيحة في المجموعة العليا - عدد الإجابات الصحيحة في المجموعة السفلي

عدد المبحوثين في إحد المجموعتين

وقد تم قبول المفردات التي يتوفر فيها الشرطين التاليين:

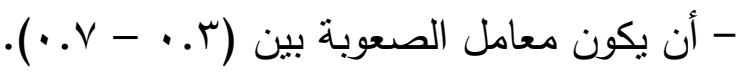

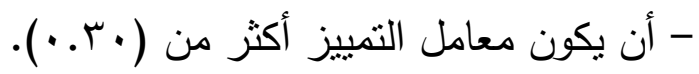
ويوضـح جـدول (0) معـاملات الصـعوبة والتمبيـز لمفـردات الاختبـار

\section{جدول (0)} المعرفي يوضتح ذلك.

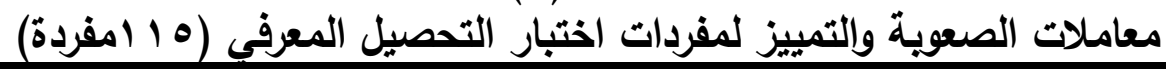

\begin{tabular}{|c|c|c|c|c|c|c|c|c|}
\hline معامل & الصعوبة & المفردة رقم & التمييز & الصعوبة & المفردة & التمييز & الصعوبة & المفردة \\
\hline$\therefore \vee \Delta$ & rr. & $\vee q$ & $\therefore 0$. & . .Or & $\varepsilon$. & .ro- & r & $* 1$ \\
\hline$\ldots v 0$ & .7 & $\Lambda$. & . ro & .. & $* \leqslant 1$ & .0 . &. $.7 \mathrm{~V}$ & r \\
\hline 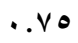 &..$\leqslant V$ & 11 & .ro- & .11 & $* \leqslant Y$ & $\therefore v_{0}$ &..$\leqslant V$ & $r$ \\
\hline .0 . & .or & $\Lambda Y$ & $\because v 0$ &.$\wedge \vee$ & $* \leqslant r$ & $1 \ldots$ & .7 & $\varepsilon$ \\
\hline$\therefore 0$. & $.7 \mathrm{~V}$ & $\Lambda r$ & $\therefore 0$. & .7. & $\leqslant \leqslant$ & .ro- &.$v r$ & *0 \\
\hline 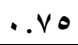 & $\cdot . \leqslant V$ & $\Lambda \varepsilon$ & .0 . & $\cdot . \leqslant V$ & $\leqslant 0$ & $\because v_{0}$ & .7. & 7 \\
\hline $1 . .$. & . . & 10 & $\therefore 0$. & .7. & $\leqslant 7$ & .ro & $\cdot . \Lambda$. & $* \mathrm{~V}$ \\
\hline .0 . & $. \quad \leqslant V$ & 19 & .0 . & . . & $\leqslant V$ &.$v 0$ & .7. & $\wedge$ \\
\hline
\end{tabular}




\section{تابع جدول (0)}

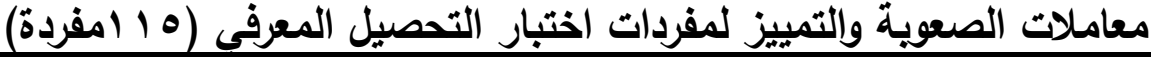

\begin{tabular}{|c|c|c|c|c|c|c|c|c|}
\hline التمبز & الصعوبة معامل & المفردمّم & التمبيز & الصعوبة معاملة & المفردمة & التمييز & الصعوبة معامل & المفردمّم \\
\hline .0 & . & AV & . vo & .7 . & $\leq \wedge$ & $\ldots$ &.$r$. & $* 9$ \\
\hline . vo &..$\Sigma V$ & ᄉᄉ &. Vo &.$\wedge V$ & $* \varepsilon 9$ & .0. & $\cdot . \leqslant V$ & 1. \\
\hline .0. & ז". & 19 & . vo & . . $\Sigma$. & 0. & 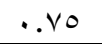 & $.7 \mathrm{~V}$ & 11 \\
\hline .100 & $\cdot . \leqslant V$ & 9. & .100 & .01 & 01 & $1 \ldots$ & .04 & 14 \\
\hline.$v 0$ & $\cdot . \Sigma$. & 91 & $1 \ldots$ & .. $\varepsilon$. & or &.$v 0$ &..$\leqslant V$ & $1 T$ \\
\hline $.0 .-$ &..$\leq V$ & $9 r$ & $.0 .-$ & $\therefore \Sigma$ & or & .0. &. $.7 \mathrm{~V}$ & $1 \varepsilon$ \\
\hline . vo &..$\wedge \mathrm{V}$ & *qr & .0. & .04 & $0 \leq$ & .0. &..$\Sigma V$ & 10 \\
\hline.$V 0$ & $\cdot . \Sigma V$ & $9 \leq$ & .0. & $\cdot . \leqslant V$ & 00 &. ro &..$\Lambda$. & $* 17$ \\
\hline $1 \ldots$ & $\cdot \ldots$ & 90 & $.0 .-$ &. $.7 \mathrm{~V}$ & 07 & $\therefore$. 0 & .01 & $1 \mathrm{~V}$ \\
\hline .0. & .7 . & 97 & $.0 .-$ &.$\leqslant \Sigma V$ & OV & $.0 .-$ &..$\varepsilon V$ & 11 \\
\hline .0. &..$\Sigma V$ & $9 V$ & $\cdots$ & $\bullet \varepsilon$. & 01 & .0 & $.7 V$ & 19 \\
\hline $1 \ldots$ &..$\Sigma$. & 91 & .0. &.$\varepsilon \varepsilon$. & 09 &. ro- & & $* r$. \\
\hline.$v 0$ &..$\Sigma V$ & 99 & $.0 .-$ & . & 7. &.$v 0$ & سז. & YI \\
\hline . Vo &..$\Sigma$. & $1 \ldots$ & .0 & 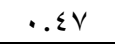 & 71 & .0. &..$\varepsilon V$ & rr \\
\hline .0. &..$\varepsilon V$ & $1 \cdot 1$ & $\cdots$ &.$r$. & *4r & .0. & .7 . & rT \\
\hline $1 \ldots$ &..$\Sigma$. & $1 \cdot r$ & .0. &. $.7 \mathrm{~V}$ & חד &.$v 0$ & . & $r \leq$ \\
\hline .0 . & .01 & $1 \cdot r$ & $\cdots$ & .7 . & $7 \leq$ & .0. & .7 & ro \\
\hline.$v 0$ &..$\varepsilon V$ & $1 \cdot \varepsilon$ & .0. & .7 . & 70 & .0. & .01 & $r T$ \\
\hline$\because v 0$ & .04 & 1.0 & $\therefore$. 0 & .7 . & 77 & .0. &.$\varepsilon$. & rV \\
\hline .0. & .01 & 1.7 & $\ldots$ vo &..$\leqslant V$ & $7 V$ & $\ldots$ Vo & .7 . & rᄉ \\
\hline .ro- &.$r V$ & $* 1 \cdot v$ & .0. & . & $7 \wedge$ & $\cdots$ &.$r$. & $* r q$ \\
\hline .0. &. $.7 V$ & $1 \cdot 1$ & .0. &..$\Sigma V$ & 79 &. ro- & ..Vr & *r. \\
\hline .0. & سM. & 1.9 & $1 \ldots$ & או.. & $V \cdot$ & .0. & .01 & M \\
\hline .0. & .7 . & 11. & 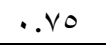 &. $.7 \mathrm{~V}$ & $V_{1}$ & .0. &..$\Sigma V$ & r \\
\hline .0. & . & 111 & . vo & .01 & Vr &.$v 0$ & .01 & rr \\
\hline.$v 0$ & .04 & 115 & .0. &..$\Sigma$. & VT & .100 &..$\varepsilon$ & $r \varepsilon$ \\
\hline .0. &..$\Sigma$ & س & $\ldots v 0$ &..$\Sigma V$ & $V \leq$ &.$V_{0}$ &. $.7 V$ & ro \\
\hline$\because v 0$ &..$\Sigma V$ & $11 \varepsilon$ & .0. & .7 & vo & $\because v 0$ & .01 & ד \\
\hline \multirow[t]{3}{*}{.0} & .7 & 110 & $1 \ldots$ &.$\Sigma$ & $V 7$ & .0 & .7 & rV \\
\hline & & & $\because v 0$ &..$\leqslant V$ & $V V$ & .0. &..$\Sigma V$ & "ᄉ \\
\hline & & &. Vo & . . & $\vee \wedge$ & . vo & $.7 V$ & rq \\
\hline
\end{tabular}


يتضـح من جدول (0) أنه قد تم إستبعاد عدد (10) عبارة لم يتوفر

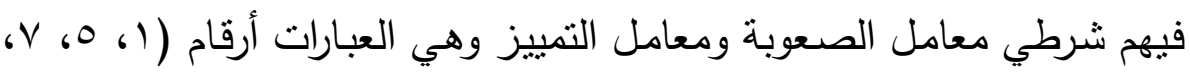

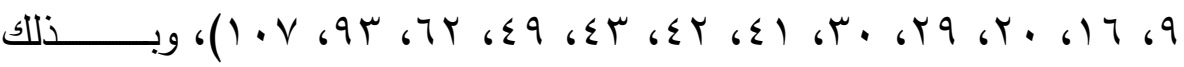

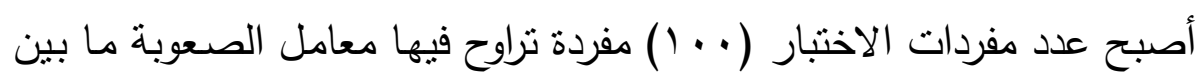

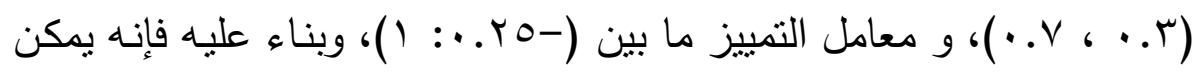

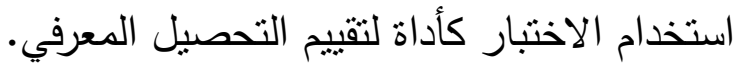

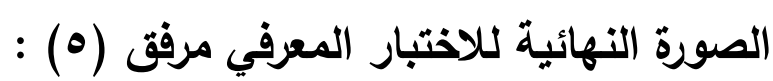
بعد عرض مفردات الاختبار الأولية على السادة الخبراء وإيجاد معاملات

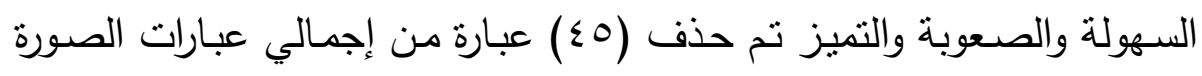

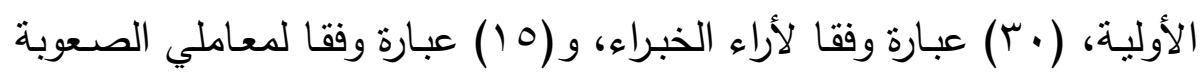

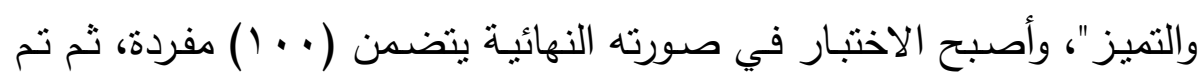
وضع المفردات في استمارة تم عرضها على مجموعة من الخبراء في مجال

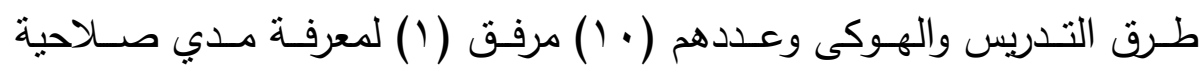
المفردات حيث اتضح موافقة الخبراء على الاختبار النهائي بنسبة مئوية قدرها

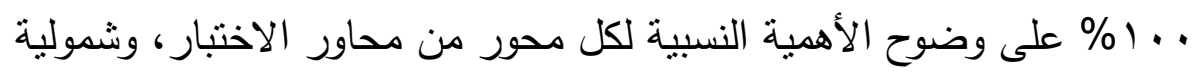

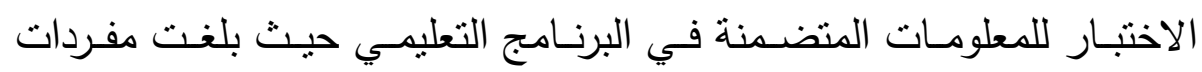

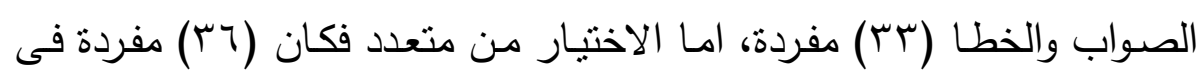

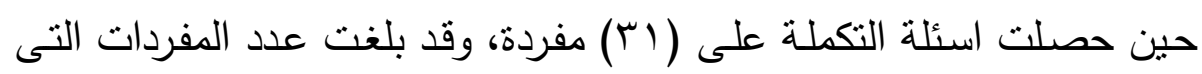

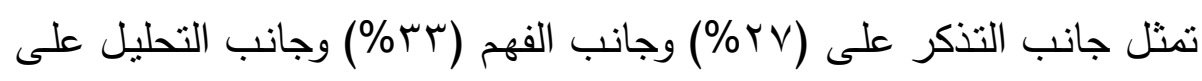

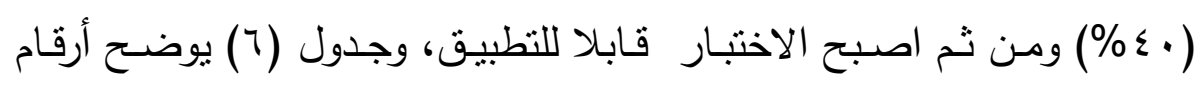
وعدد مفردات كل محور في الثكل النهائي.

\section{جدول رقم (؟)}


محاور ومفردات وارقام والاهمية النسبية للمستويات المعرفية الاختبار

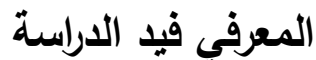

\begin{tabular}{|c|c|c|c|c|c|c|c|c|c|c|c|c|c|c|}
\hline \multirow{2}{*}{\multicolumn{2}{|c|}{ الاهمية }} & \multirow{2}{*}{\multicolumn{6}{|c|}{ المستويات المعرفية }} & \multirow{4}{*}{ ألمفردات } & \multirow{4}{*}{$\begin{array}{l}\overline{3} \\
\frac{3}{3} \\
\overline{3} \\
\frac{3}{3}\end{array}$} & \multicolumn{3}{|c|}{ نوع الأسئلة } & \multirow{4}{*}{ الاختبار } & \\
\hline & & & & & & & & & & & 雪。 & ఫ & & \\
\hline \multirow{2}{*}{ ๙ } & \multirow{2}{*}{$\overline{7}$} & \multicolumn{2}{|c|}{ التحليل } & \multicolumn{2}{|c|}{ الفهم } & \multicolumn{2}{|c|}{ التذكر } & & & 隶 & .3 & $\stackrel{5}{9}$ & & \\
\hline & & $\%$ & العدد & $\%$ & العدد & $\%$ & العدد & & & & 疍 & $g$ & & \\
\hline 1. & 1. & - & - & - & - & $1 \ldots$ & 1. & 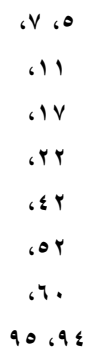 & 1. & $r$ & $r$ & 0 & ونثأة & 1 \\
\hline$\leqslant r$ & $\leqslant Y$ & ד.V & $r \wedge$ & rr.A & 1. & 9.0 & $\varepsilon$ & 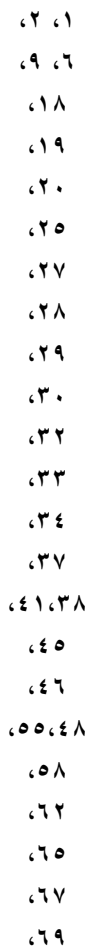 & $\leqslant Y$ & 1. & 11 & $1 \varepsilon$ & الهوكى & $r$ \\
\hline
\end{tabular}

تابع جدول رقم (7) - (7)

مجلة أسيوط لعلوم وفنون التربية الرياضية 
محاور ومفردات وارقام والاهمية النسبية للمستويات المعرفية الاختبار المعرفي فيد الدارية المبنة

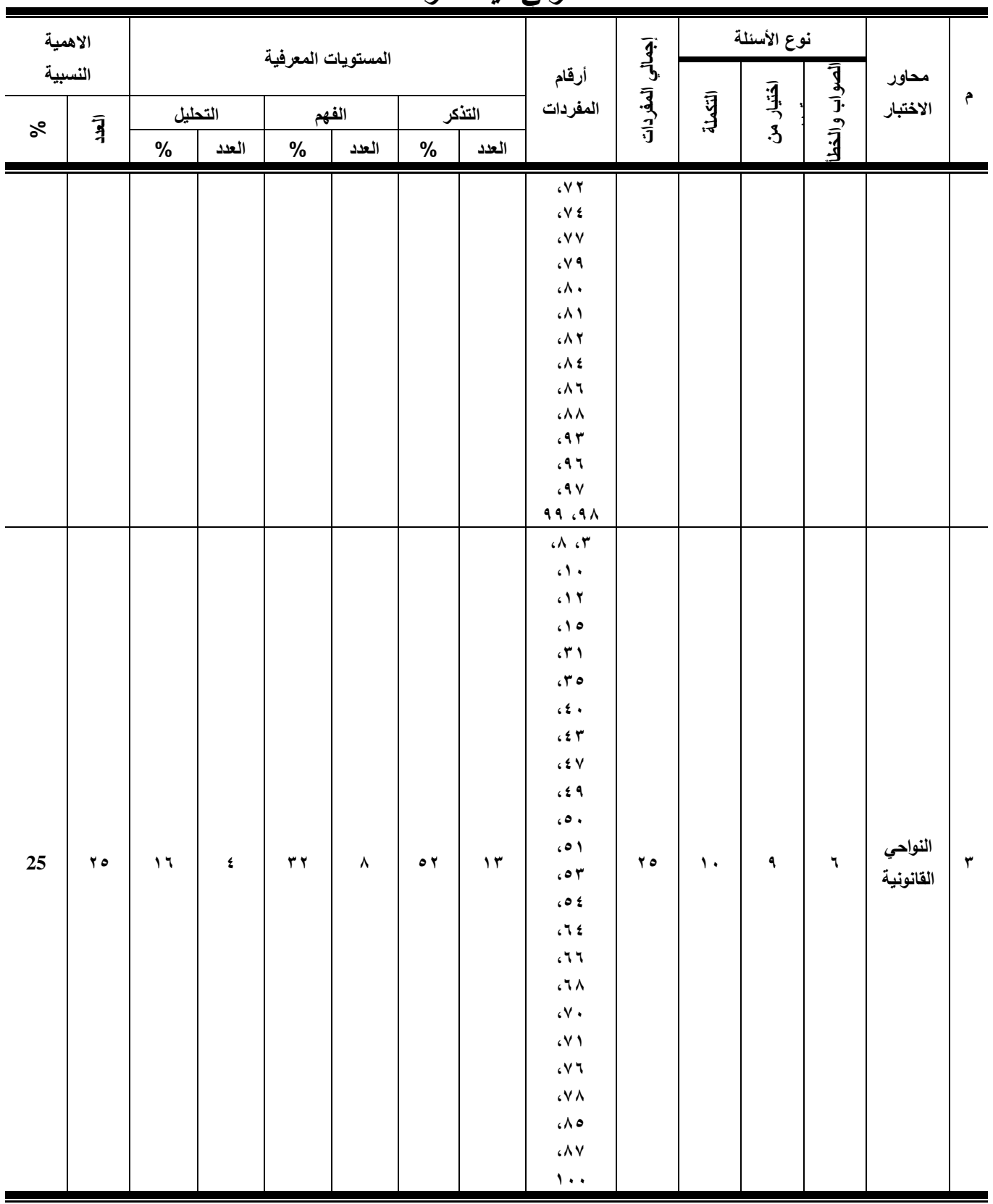

تابع جدول رقم (؟)

مجلة أسيوط لعلوم وفنون التربية الرياضية 
محاور ومفردات وارقام والاهمية النسبية للمستويات المعرفية الاختبار

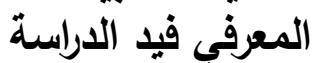

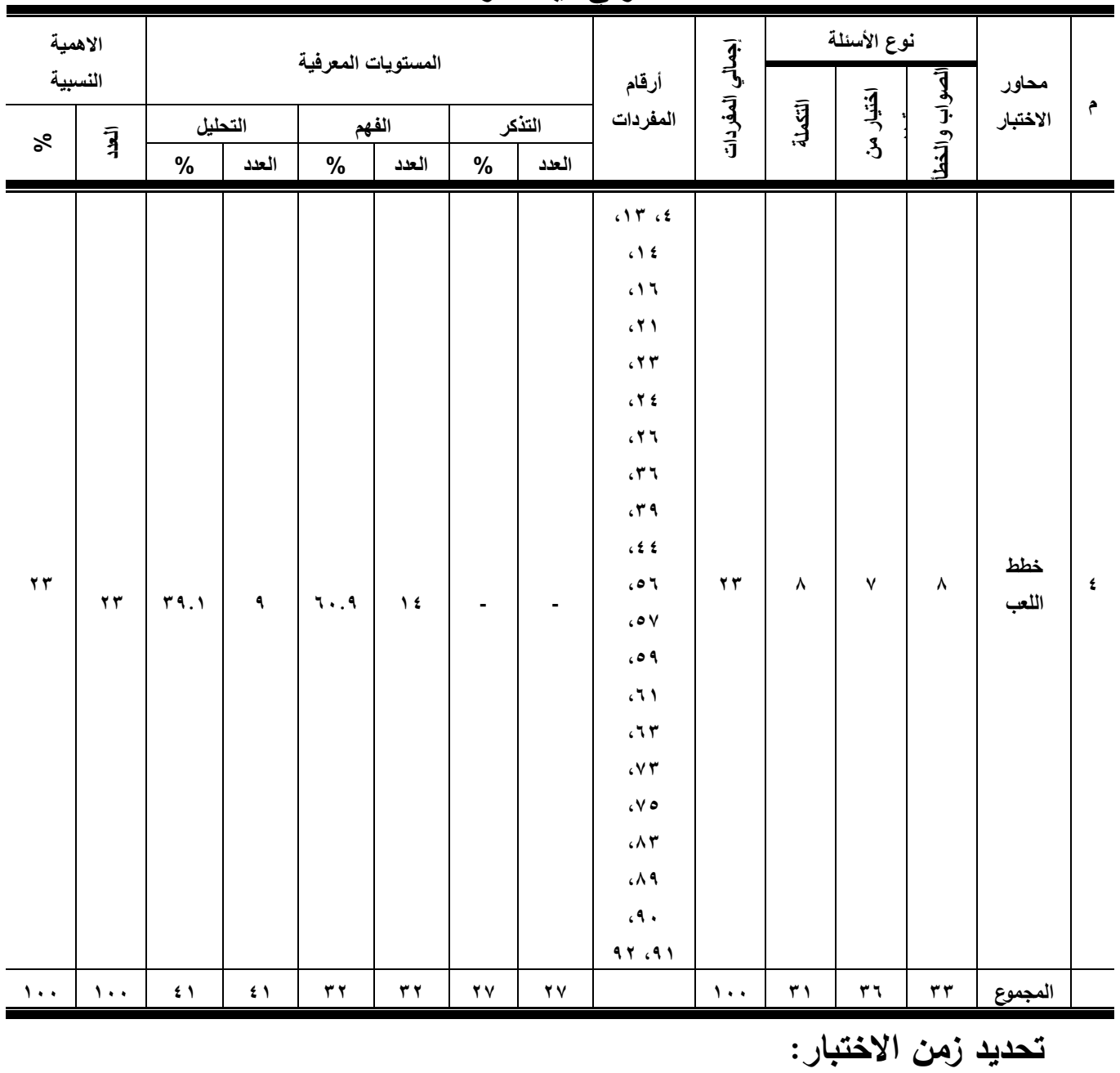

قام الباحثُون بتحديد الزمن المناسب للإجابة على الاختبار في ضوء

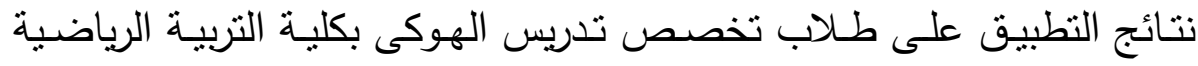

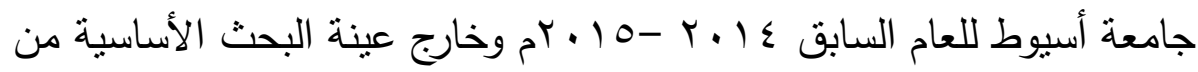

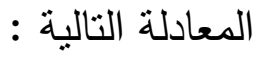
الزمن الذي استغرقه أول طالب + الزمن الذي استغرقه آخر طالب

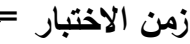
مجلة أسيوط لعلوم وفنون التربية الرياضية 
وبذلك آمكن تحديد الزمن الكلي للاختبار وهو ( • (0 ) دقيقة. تقديرات الدرجات وطريقة التصحيح : روعي عند التصـيح أن تعطى درجـة واحدة لكل إجابـة صـحيحة مـن

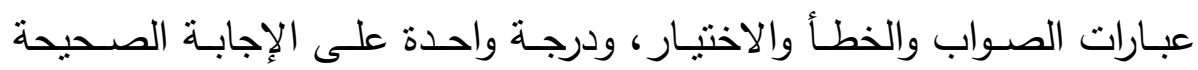
لعباراة التكملة، وصفر لكل إجابة خاطئة، وبالتالي تكون الدرجة الكلية لاختبار التحصيل المعرفي من ( . () درجة، وقد تم إعداد مفتاح التصـيح لتسـيل عملية التصحيح مرفق رقم(T). المعاملات العلمية للاختبار المعرفي : قام الباحثون بتطبيـق الاختبـار على مجموعـة استطلاعية قوامها (· (1) طالب مـن طـلاب تخصـص تدريس الهـوكى بكليـة التربيـة الرياضـية جامعـة

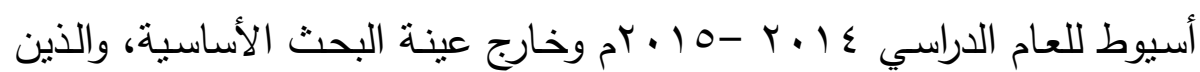
درسوا نفس المحتوى العلمي لمنهج تدريس هوكى الميدان وتم رصد الدرجات تمهيدا لحساب المعاملات الإحصائية والعلمية للاختبار . صدق الاختبار المعرفي : قام الباحثون بايجاد صدق الاختبار من خلا صدق المحكمين وصدق : التمايز كالتالى: أ- صدق المحكمين : قام الباحثون بعرض الاختبار على ( • () من الخبراء في مجال المناهج وطرق التدريس والهوكى مرفق (1) لإبداء الرأي في الاختبار وملاحظة مفرداته

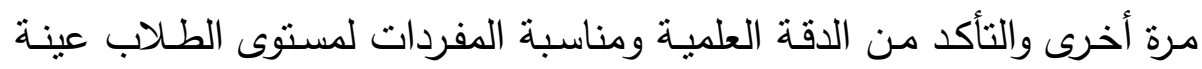
البحث وتتاسبها مع كل محور من محاور الاختبار ومن ثم صلاحيتها للتطبيق ونه

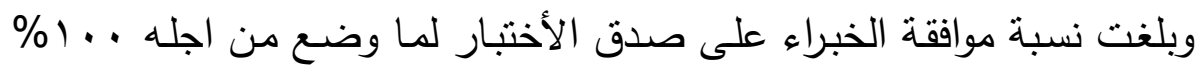


وبـذلك أصبـح الاختبـار في شكله النهائي مكون مـن ( . . () مفردة صـالحة للتطبيق

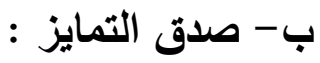

قـام الباحثون بتطبيق الاختبـار على مجموعـة استطلاعية قوامها ( ( ) طلاب من طلاب تخصص تدريس الهوكى الفرقة الرابعة بكلية التربية الرياضية

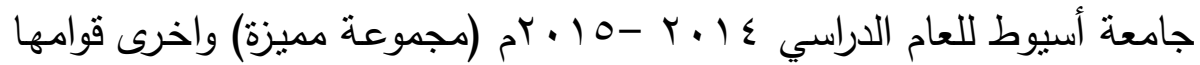
( • (1) من طلاب الفرقة الثالثة من مجتمع البحث وخارج عينة البحث الأساسية

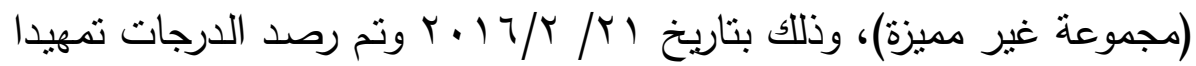
لحساب المعاملات الإحصائية والعلمية للاختبار • جدول

دلالة الفروق بين متوسط الاختبار المعرفي للمجموعتين المميزة وغيرالمميزة ( $r$. $=$

\begin{tabular}{|c|c|c|c|c|c|c|c|}
\hline \multirow{2}{*}{ قيمة"ت" } & \multicolumn{2}{|c|}{ غير المميزة } & \multicolumn{2}{|c|}{ المميزة } & \multirow[b]{2}{*}{ وحدة القياس } & \multirow[b]{2}{*}{ المتــــــــير } & \multirow[b]{2}{*}{ r } \\
\hline & الإنحر اف & المتوسط & الإنحر اف & المتثابط الحسبي & & & \\
\hline ro,r. & r.. 9 & YI.VT & $1.9 V$ & $V \varepsilon .1$. & درجة & المعرفي $\quad$ التحصيل & 1 \\
\hline
\end{tabular}

يتضح من جدول (V) وجود فروق دالة إحصائيا بين المجموعتين المميزة وغيرالمميزة في درجـات الاختبـار المعرفي لصـالح المجموعـة المميزة

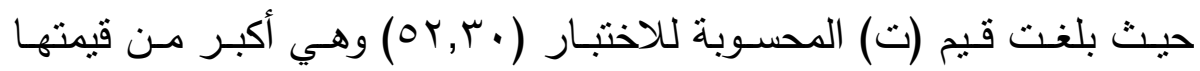
الجدوليـة عند مسـتوى (0 . . ) ممـا يثـير الى صـدق الاختبـار المعرفي قيد البحث.

ثبات اختبار التحصيل المعرفي: قام الباحثون بحساب ثبات اختبار التحصيل المعرفى وذلك بتطبيقه وإعادة

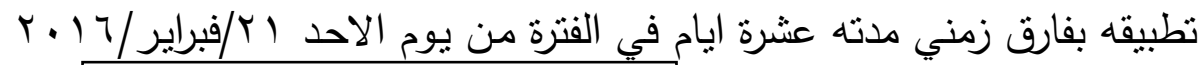
مجلة أسيوط لعلوم وفنون التربية الرياضية 


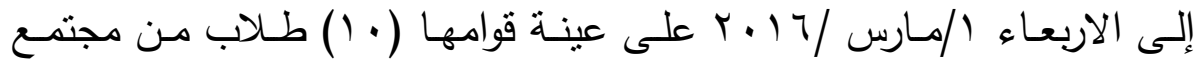

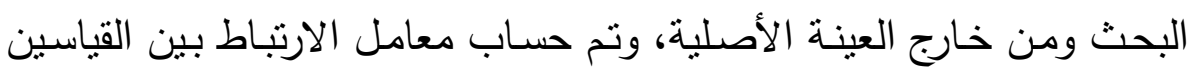
وجدول (^) يوضح معاملات الارتباط بين القياسين.

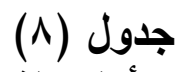

معاملات الإرتباط بين التطبيق الأول والثاني للاختبارالمعرفي (ن= • 1)

\begin{tabular}{|c|c|c|c|c|c|c|c|}
\hline \multirow{2}{*}{ قليمسوبر" } & \multicolumn{2}{|c|}{ التطبيق الثاني } & \multicolumn{2}{|c|}{ التطبيق الأول } & \multirow{2}{*}{ والقياس } & \multirow{2}{*}{ المتفــــيرات } & \\
\hline & المعياري & الحسابي & المعياري & الحستابي & & & \\
\hline$* . . \wedge 7$ & $r . .$. & rr.\&T & r.A9 & $r . . K r$ & درجة & التحصبيل & \\
\hline
\end{tabular}

يتضح من جدول (^) وجود ارتباط دال إحصائياً بين التطبيق وإعادة النطبيق فى اختبار التحصيل المعرفي، حيث بلغت قيمة "ر" المحسوبة

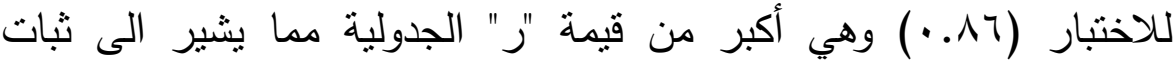

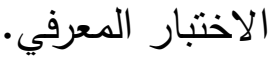

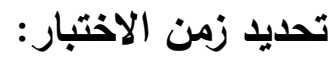

قام الباحثون بتحديد الزمن المناسب للإجابة على الاختبار في ضوء

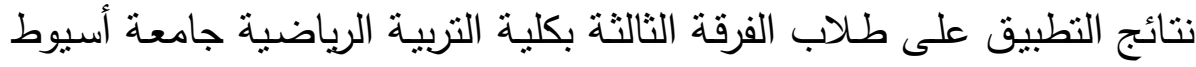

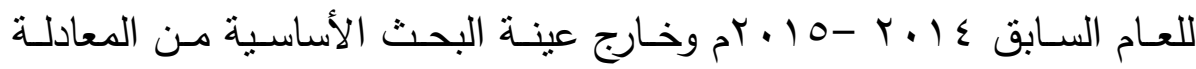

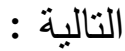

الزمن الذي استغرقه أول طالب + الزمن الذي استغرقه آخر طالب r

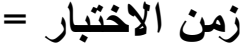
وبذلك آمكن تحديد الزمن الكلي للاختبار وهو (•) دقيقة. مجلة أسيوط لعلوم وفنون التربية الرياضية التية 


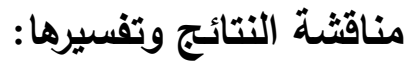

بناء علي نتائج التحليل الإحصائي لبيانات البحث واسترشادا بالمراجع العلمية والدراسات السابقة يقدم الباحثون فيما يلي عرض تفصيلي لنتائج البحث الحالي في ضوء هدف وتساؤل البحث: بناء الاختبار المعرفي في لعبة الهوكى للمرحلة التخصصية بكليات التربية

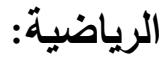

بناء علي نتائج التحليل الإحصـائي لبيانـات البحث (التوزيع النسبي

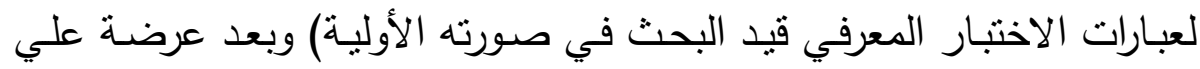
الخبراء وبعد حساب معاملات السهولة والصعوبة والتمييز ، توصل الباحثون إلي بناء اختبار معرفي في لعبة الهوكى لطلاب المرحلة التخصصية بكليات التربية الرياضية، وقد احتوي الاختبار في صورته النهائية علي (؟) محاور

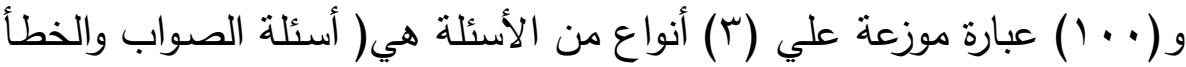

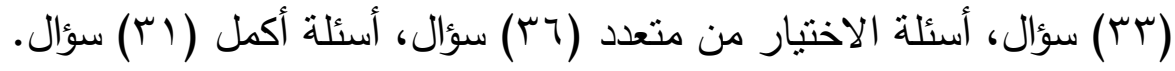
وقد حقق الاختبار معاملات صدق وثبات عالية حيث تراوح معامل الارتباط بين التطبيق الأول والنطبيق الثاني عند حساب الثبات (7 (1. •)، وهو دال إحصائيا عند مستوي (0.,.)، كما تحقق صدق المحتوبي للاختبار المعرفي

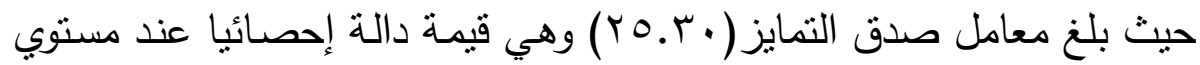

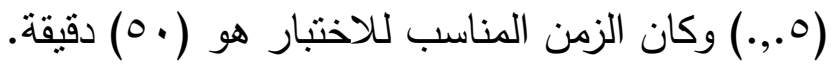

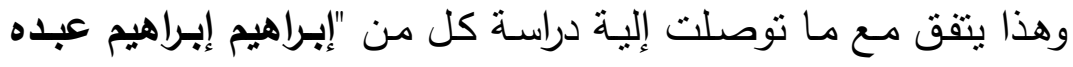

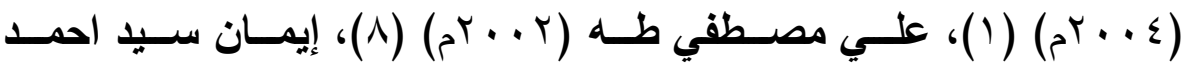

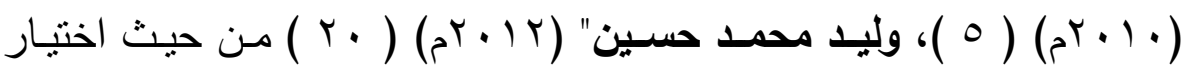

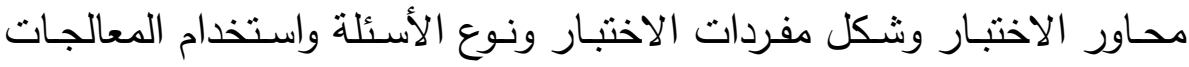
الإحصائية المناسبة لطبيعة البحث. مجلة أسيوط لعلوم وفنون التربية الرياضية 
كما تتفق هذه النتائج مـع مـا أثـار إلية "أمين أنور الخولي، محمود عبد القتـاح عنـان" (999 (م) نقلا عن هارا Harra ان تعليم القدرات العقلية المعرفية يعتبر من أهم الجوانب التي لا يمكن الاستغناء عنها في مراحل تعليم

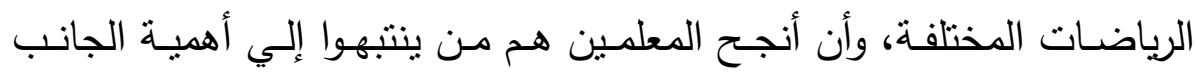

المعرفي العقلي وخططوا لإكساب المعارف النظرية للطلاب (r: (ب-r آT) وبهذا يتحقق هدف البحث وهو بناء اختبار معرفي في الهوكى لطلاب المرحلة التخصصية بكليات التربية الرياضية بمكن الاعتمـاد عليـة في قياس الجوانب المعرفية.

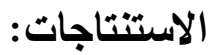

في ضوء أهداف البحث وفي حدود عينة البحث والإجراءات المتبعة

توصل الباحثون إلي النتائج التالية : 1- بناء اختبار معرفي في لعبة الهوكى لطلاب المرحلة التخصصية بكليات التربية الرياضية.

r- اشتمل الاختبـار في صسورته النهائيـة علي (r) محساور و( · · ( ) عبـارة موزعـة علي (ب) أنسواع من الأسئلة هي( أسئلة الصـواب والخطأ (سب)

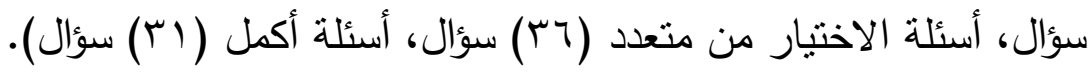
ب- يمكن الاعتمـاد عليـة في قيـاس الجوانـب المعرفيـة بعد أن تم اسـتخراج معامل السهولة والصعوبة والتمييز والصدق والثبات.

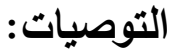

في ضوء نتائج البحث يوصي الباحثون بما يلي: - - استخدام الاختبـار المعرفي في الهوكى قيد البحث بصورة دوريـة لتقويم طلاب المرحلة التخصصية بكليات التربية الرياضية بجانب الاختبارات البدنية والمهارية. 
- - بناء الاختبارات المعرفية المناسبة للمراحل السنية المختلفة في لعبة هوكى الميدان والرياضات الاخري.

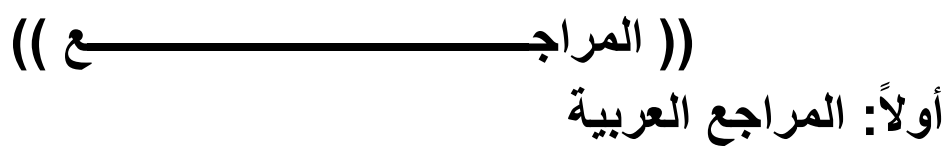

1- ابراهيم ابراهيم عبده (9 + . r م): تأثير برنامج باستخدام الوسائط المتعددة التفاعلية علي الدافعية والتحصيل المعرفي ومستوي الاداء الحركي للمبتدئين في رياضة الماكمة، رسالة دكتوراة، كلية التربية الرياضية ،جامعة المنصورة. r - أمين أنور الخولي، جمال الدين عبد العاطي الثافعي (1 +. ب م): مناهج التربية البدنية المعاصرة، دار الفكر العربي، القاهرة.

r- امين انور الخولى، محمود عنان(9 9 أم): المعرفة الرياضية، دار الفكر العربي، القاهرة.

ع- إيلين وديع فرج (^ . . rم): هوكى الميدان الاسس العلمية والتدربيية، منشاة المعارف، الإسكندرية. 0- ايمان سيد احمد( • • • م): برنامج الكتروني مقترح لتعليم مهارات الكرة

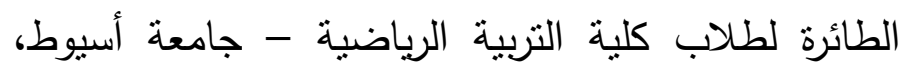
رسالة دكتوراه، كلية التربية الرياضية، جامعة اسيوط. 7- طارق محمد خليل (צ9 9 (م)): بناء بطارية اختبارات مهاربة بدنية لناثئ الهوكى تحت با سنة، رسالة ماجستير، كلية التربية

$$
\text { الرياضية بنين، جامعة حلوان. }
$$

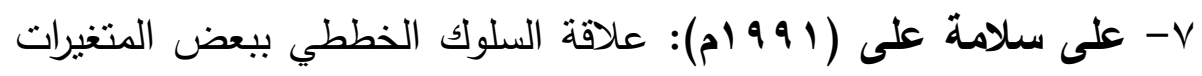
البدنية والمهارية والنفسية للاعبي الهوكي، رسالة دكتوراه، كلية التربية الرياضية بنين، جامعة حلوان. 
1- على مصطفى طه (ץ . r م): بناء اختبار معرفي فى الكرة الطائرة لطلاب كلية التربية الرباضية شعبة تعليم،المجلة العلمية، العدد الخامس، كلية التربية الرياضية ببورسعيد، جامعة قناة

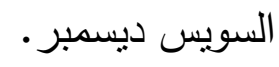

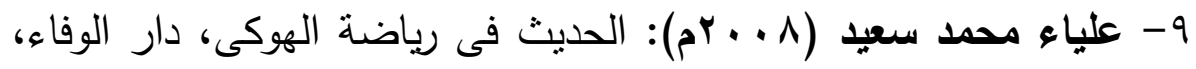
الإسكندرية.

• 1- ليلي السيد فرحات (1 . . rم): القياس المعرفى الرياضي، مركز الكتاب للنشر، القاهرة.

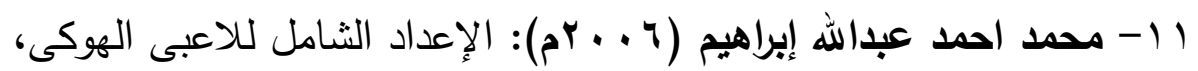
مركز آيات للطباعة والكمبيوتز ، الزقازيق.

r ا- محمد حسن علاوى، محمد نصر الدين رضوان( ( +. r.م): اختبارات الاداء الحركى، طء، دار الفكر العربى، القاهرة.

r ا- محمد صبحي حسانين ( . . . rم): القياس والتقويم في التربية الرياضية، طء، دار الفكر العربي ،القاهرة.

ء ا- محمد محمد الحماحمي، أمين أنور الخولي (99 (9)م): أسس بناء برامج التربية الرياضية ،دار الفكر العربي، القاهرة. 1 - محمد محمد الشحات (99V (م): دليل الألعاب الرياضية الجماعية، لرئه مكتبة الإيمان، المنصورة.

7 ا - محمد محمد الثحات (Y . . Y م): تأثثر استخدام اسلوبى التعلم التعاونى والاوامر على اداء بعض مهارات اللعب بالوجه المعكوس

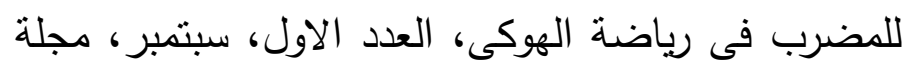
كلية التربية الرياضية، جامعة المنصورة.

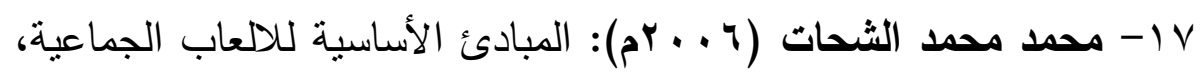
مكتبة شجرة الار، المنصورة. 
11- منذر محمد كمال (999 (9): أثز استخدام مدخلين في تدريس الرياضيات باستخدام الحاسب الآلي علي تحصيل تلاميذ الصف الإعدادي واستيفاء أثز تعلمهم لها واتجاهاتهم

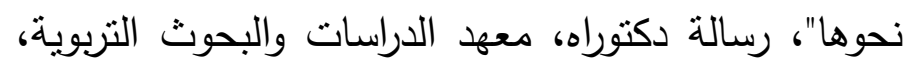
جامعة القاهرة.

9 1 - منير جرجس ابراهيم، محمد حسن علاوى(999) (م): الهوكى تاريختدربب- تحكيم، دار المعارف، القاهرة.

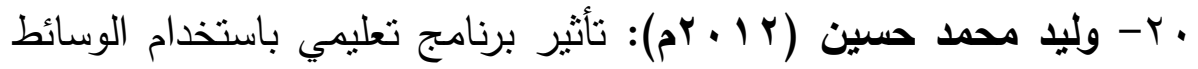

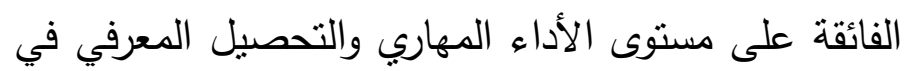
كرة السلة لاى طلاب الفرقة الثانية بكلية التربية الرياضية

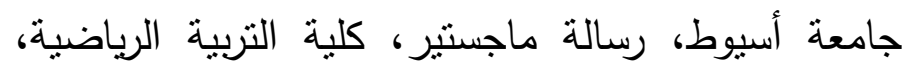
جامعة أسيوط.

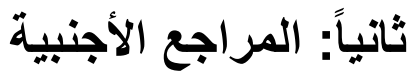

21. Carl word (1989): Play the Game Hochey, Byword lock limited, Clifford Company.

22. Isabel waker(2001): Why visual training programmes for sport don't work, Sports Sci,Mar 19(3)p203-22.

23. John Law (1990): How to Coach Hockey, willow Books, willian Collins Sons \& Coltd, London Glasgow. Sydney. Auckland, Toronto, Johann Esbutg.

24- Podesta, T. (1982): Hockey for men and women, E.p.publishing L.T.D London. 